University of Wollongong

Research Online

Australian Institute for Innovative Materials -

Papers

Australian Institute for Innovative Materials

$1-1-2019$

Emerging approach in semiconductor photocatalysis: Towards 3D architectures for efficient solar fuels generation in semi-artificial photosynthetic systems

Chong Yong Lee

University of Wollongong, cylee@uow.edu.au

Jinshuo Zou

University of Wollongong, jz940@uowmail.edu.au

John P. Bullock

Bennington College

Gordon G. Wallace

University of Wollongong, gwallace@uow.edu.au

Follow this and additional works at: https://ro.uow.edu.au/aiimpapers

Part of the Engineering Commons, and the Physical Sciences and Mathematics Commons

Research Online is the open access institutional repository for the University of Wollongong. For further information contact the UOW Library: research-pubs@uow.edu.au 


\title{
Emerging approach in semiconductor photocatalysis: Towards 3D architectures for efficient solar fuels generation in semi-artificial photosynthetic systems
}

\author{
Abstract \\ Interest in the application of semiconductors toward the photocatalytic generation of solar fuels, \\ including hydrogen from water-splitting and hydrocarbons from the reduction of carbon dioxide, remains \\ strong due to concerns over the continued emission of greenhouse gases as well as other environmental \\ impacts from the use of fossil fuels. While the efficiency and durability of such systems will depend \\ heavily on the types of the semiconductors, co-catalysts, and mediators employed, the dimensionality of \\ the semiconductors employed can also have a significant impact. Recognizing the broad nature of this \\ field and the many recent advances in it, this review focuses on the emerging approaches from \\ 0-dimensional (OD)to 3-dimensional (3D)semiconductor photocatalysts towards efficient solar fuels \\ generation. We place particular emphasis on systems that are "semi-artificial", that is, hybrid systems that \\ integrate naturally occurring enzymes or whole cells with semiconductor components that harvest light \\ energy. The semiconductors in these systems must have suitable interfacial properties for immobilization \\ of enzymes to be effective photocatalysts. These requirements are particularly sensitive to surface \\ structures and morphology, making the semiconductor dimensionality a critical factor. In addition to \\ providing an overview of advances towards designing 3D architecture in semi-artificial photosynthetic \\ field, we also present recent advances in fabrication strategies for 3D inorganic photocatalysts. \\ Disciplines \\ Engineering | Physical Sciences and Mathematics

\section{Publication Details} \\ Lee, C., Zou, J., Bullock, J. \& Wallace, G. G. (2019). Emerging approach in semiconductor photocatalysis: \\ Towards 3D architectures for efficient solar fuels generation in semi-artificial photosynthetic systems. \\ Journal of Photochemistry and Photobiology C: Photochemistry Reviews, 39 142-160.
}




\title{
Emerging approach in semiconductor photocatalysis: towards
}

\section{D architectures for efficient solar fuels generation in semi-}

\author{
artificial photosynthetic systems
}

Chong-Yong Lee ${ }^{1 *}$, Jinshuo Zou ${ }^{1}$, John Bullock ${ }^{2}$, and Gordon G. Wallace ${ }^{1}$

\footnotetext{
${ }^{1}$ ARC Centre of Excellence for Electromaterials Science, Intelligent Polymer Research Institute, AIIM, Innovation Campus, University of Wollongong, Wollongong, NSW 2500, Australia.

${ }^{2}$ Division of Natural Science and Mathematics, Bennington College, Bennington, Vermont 05257, USA.
}

Corresponding author:

E-mail address: cylee@uow.edu.au (C.-Y. Lee)

\section{Contents}

1. Introduction

2. Hybrid semiconductor-bioinorganic photocatalytic systems

2.1 Enzymatic photocatalytic hydrogen evolution

2.2 Enzymatic photocatalytic carbon dioxide reduction

3. Hybrid semiconductor-bioinorganic photoelectrochemical systems

3.1 Conventional electrode architectures

3.2 Advanced electrode architectures

4. Other functional 3D architectures in photocatalytic systems

4.1 3D stuctures for enzyme protection

4.2 3D-printed advanced structures

4.3 3D-structures assembled from 2D nanosheets

5. Conclusion and outlook 
Abstract: Interest in the application of semiconductors toward the photocatalytic generation of solar fuels, including hydrogen from water-splitting and hydrocarbons from the reduction of carbon dioxide, remains strong due to concerns over the continued emission of greenhouse gases as well as other environmental impacts from the use of fossil fuels. While the efficiency and durability of such systems will depend heavily on the types of the semiconductors, cocatalysts, and mediators employed, the dimensionality of the semiconductors employed can also have a significant impact. Recognizing the broad nature of this field and the many recent advances in it, this review focuses on the emerging approaches from 0-dimensional (0D) to 3dimensional (3D) semiconductor photocatalysts towards efficient solar fuels generation. We place particular emphasis on systems that are "semi-artificial", that is, hybrid systems that integrate naturally occurring enzymes or whole cells with semiconductor components that harvest light energy. The semiconductors in these systems must have suitable interfacial properties for immobilization of enzymes to be effective photocatalysts. These requirements are particularly sensitive to surface structures and morphology, making the semiconductor dimensionality a critical factor. In addition to providing an overview of advances towards designing 3D architecture in semi-artificial photosynthetic field, we also present recent advances in fabrication strategies for 3D inorganic photocatalysts.

Keywords: semiconductor; photocatalysis; dimensionality; semi-artificial photosynthesis; solar fuels; enzyme 


\section{Introduction}

Since the demonstration of stoichiometric splitting of water using an illuminated $\mathrm{TiO}_{2}$ semiconductor electrode by Honda and Fujishima in 1972 [1], and the ensuing oil crisis that followed soon thereafter, there has been intense interest in the use of semiconductor materials for photo-driven hydrogen production and related technologies. For example, research in heterogeneous photocatalysis by $\mathrm{TiO}_{2}$ was very active in the 1980s [2-5] and was eventually applied to related environmental remediation processes, such as the photodegradation of pollutants, self-cleaning surfaces, and air purification [6-18]. More recently, the drive to reduce greenhouse gas emissions and to generate chemical feedstocks with smaller carbon footprints have provided further impetus to this line of research $[19,20] . \mathrm{TiO}_{2}$ and other oxide and nitridebased semiconductors have been examined to this end, as have a host of metallic, non-metallic and carbon-based semiconducting materials [21-35].

The photocatalytic activities of all semiconductors, either as suspended particles (Figure 1a) or solid-state electrodes (Figure 1b) involve the following fundamental processes [[8, 9, 11]. Pairs of charge carriers are produced via the absorption of photons having energy equal to or greater than the semiconductor band gap; electrons promoted from the valence band (VB) to the conduction band (CB) serve as negative charge carriers, while the electron holes generated in the VB serve as positive charge carriers. In many cases, the photogenerated electrons and holes recombine, thereby converting the absorbed light energy to heat and decreasing the catalytic efficiency of the process. If recombination of the charge carriers does not occur they can participate in redox reactions, wherein the holes in the valence band serve as oxidizing agents, either by direct reaction with a substrate or indirectly via the formation of surface-bound hydroxyl radicals $[11,13]$. Analogous processes can occur in the conduction band, wherein electrons migrate to the surface of the semiconductor and serve to reduce reactants at the catalyst surface. For solar fuel production, the reduction of solvated protons to 
hydrogen, and the reduction of $\mathrm{CO}_{2}$ to gaseous and liquid hydrocarbons, are among the processes of greatest interest owing to their obvious utility in the realization of a hydrogen economy and recycling of $\mathrm{CO}_{2}$ to chemical feedstocks.

To achieve desirable selectivity and efficiency of such photo-initiated redox processes, much work has been done to incorporate co-catalysts at semiconductor surfaces. Of particular interest has been the coupling of naturally occurring enzymes, particularly oxido-reductases, to semiconductors [36-38]. Enzymes such as hydrogenases and formate dehydrogenases show high reversibility in proton reduction/oxidation, and $\mathrm{CO}_{2}$ reduction/oxidation processes. Enzymes have exceptionally high specificities and selectivities and operate at low overpotentials, thereby minimizing energy losses. They are readily operated at room temperature in neutral $\mathrm{pH}$. As such, their characteristics are unrivalled by synthetic catalysts. Indeed, one of the chief problems with using enzymatic co-catalysts is the difficulty of purifying these protein species, but recent work using whole cells has demonstrated that such steps may not always be necessary.

Combining inorganic photocatalysts with enzymatic catalysts or whole cells allows for the mimicry of naturally occurring photosynthetic processes. This hybridization also makes use of some advantageous properties of semiconductors, specifically the wide range of wavelengths they can absorb and their greater stability, both of which easily exceed the corresponding aspects of photosynthetic enzymes. Finally, this approach can be extended to non-photosynthetic bioinorganic enzymes; in principle, any oxidoreductase can make use of a semiconductor photocurrent. In the context of this review, isolated enzymes are highly efficient benchmark biocatalysts, and the challenge is to effectively and optimally couple their catalytic properties to a semiconductor surface. As such, a critical aspect of such work is the examination of the role and properties of the photocatalysts employed and, as we emphasize, their dimensionality is a key factor in overall catalytic performance. 
(a)

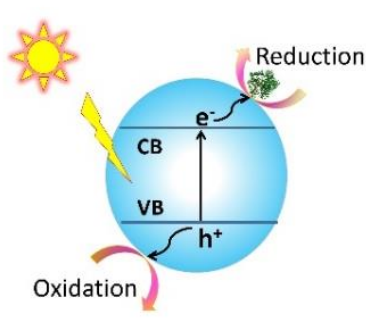

Photocatalysis

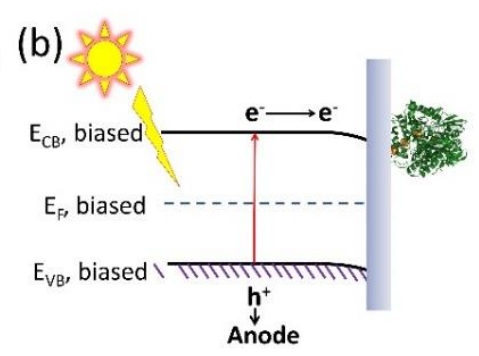

Photoelectrocatalysis

(c)

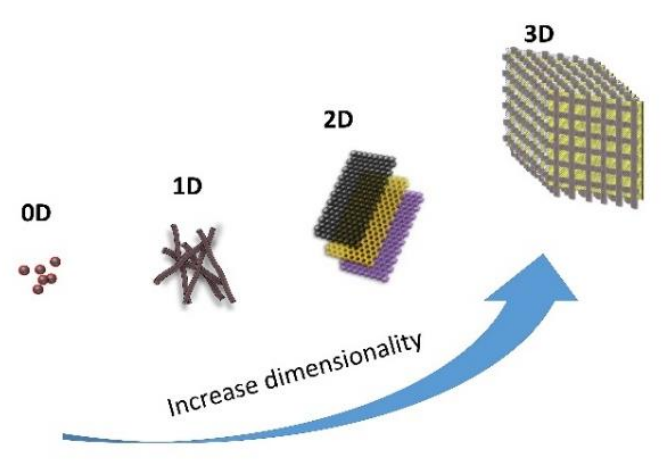

Figure 1 The formation of photogenerated charge carriers (holes and electrons) upon absorption of light with energies corresponding to the band gap of semiconductors in (a) suspended semiconductor particles and (b) solid-state electrodes; the latter illustrates band positions of $p$-type semiconductor upon applied bias potential. (c) Illustration of structural dimensionality of photocatalysts from zero to three dimensions.

The overall efficiency, robustness, and efficacy of any photocatalytic process involving semiconductors and co-catalysts will depend, obviously, on the nature of these materials themselves, but also by how they are structured. This is because the manner by which cocatalysts are immobilized onto the semiconductor surface can strongly affect the rate of charge recombination, a critical determinant of the overall process efficiency, as well as the relevant chemical kinetics. Moreover, the morphology and dimensionality of the semiconductor material can have a significant impact of photocatalytic performance; properties such as 
particle size, specific surface area, crystalline structure and phase, and the nature of exposed facets, all influence catalytic behavior. As such, modification of the dimensional properties of photocatalysts (Figure 1c) can greatly impact the efficacy of a given combination of semiconductor and cocatalyst. Zero-dimension (0D) photocatalysts, for example, have an exceptionally high surface area and can exhibit correspondingly higher rates of photocatalytic reactions. One-dimensional (1D) fibers, rods or tubes have desirable light scattering properties and have been shown to have very low rates of charge recombination owing to the short distances required for charge carrier diffusion [39, 40]. Two-dimensional (2D) nanosheets have recently attracted attentions for solar fuel generation, with the bandgaps found to be a sensitive function of the nanosheet thickness, whereby ultrathin 2D semiconductors reduce migration distance from the bulk to the surface and have abundant reaction sites [29]. Finally, threedimensional (3D) structures of the appropriate morphology may have excellent charge carrier mobility owing to interconnecting structures; they can also have very higher surface areas for the same reason and can be particularly well-suited for device-type applications.

In this review, we focus on emerging aspects of research on semiconductor photocatalysis for solar fuel generations with particular emphasis on the effect of semiconductor dimensionality, ranging from $0 \mathrm{D}$ to $3 \mathrm{D}$ architectures. We highlight the benefits of $3 \mathrm{D}$ architectures in hybrid artificial photosynthetic systems that employ biological enzymes in the generation of chemical fuels. The results featured are also generally applicable to other photocatalytic systems. In addition, we provide an overview of recent advancement in design and fabrication of 3D architectures, via material synthesis and 3D printing strategies, of inorganic photocatalytic systems. 


\subsection{Hybrid semiconductor-bioinorganic photocatalytic systems}

There has been much attention given to the development of hybrid semiconductorenzymatic systems, owing to the efficiency of enzymes in catalyzing a host of redox processes [41-43]. Such systems typically consist of enzymes adsorbed or covalently linked to semiconductor surfaces and share the functionalities of metallic or inorganic-based photocatalysts. In addition, a recently emerging approach employs whole cells of bacteria or microorganisms in conjunction with semiconductors. Both approaches achieve synergetic integration of light-harvesting nanomaterials with highly efficient catalysts for solar fuel production. These hybrid systems have been referred to in the literature as 'photobiohybrid', 'photobiocatalysis' and 'semi-artificial photosynthesis', the latter term distinguishing these systems from "artificial photosynthesis" which relies entirely on synthetic materials.

In this section, we discuss semi-artificial approaches for photocatalytic hydrogen evolution and carbon dioxide reduction. Our focus is on the impact of semiconductor dimensionality towards photocatalytic performances, especially enzymatic-semiconductor systems. Semiconductor-bioinorganic performance is typically based on parameters such as turn over frequencies (TOFs), apparent quantum yield (AQY) and quantum efficiency (QE), but it is worth noting the following caveat. Because some enzymes and whole-cells are susceptible to photodegradation, in addition to possessing unique optimal specific absorption wavelengths, types of light sources, such as monochromatic light, or solar simulator, are not uniformly used when characterizing photoefficiency, making direct performance comparisons between various systems difficult. 


\subsection{Enzymatic photocatalytic hydrogen evolution}

Biohydrogen production represents a promising approach to realizing a hydrogen economy [44, 45]. Hydrogenases are extremely active microbial enzymes that catalyze the reversible reduction of protons to molecular hydrogen, with reported turnover frequencies exceeding $1,000 \mathrm{~s}^{-1}$ under ambient conditions $[42,46]$. [FeFe] and [NiFe] hydrogenases have been widely investigated in hybrid semiconductor-bioinorganic photocatalytic systems. A variation of $[\mathrm{NiFe}]$ is $[\mathrm{NiFeSe}]$ where one of two terminal cysteines is replaced by selenocysteine [46, 47]. These typically contain multiple iron-sulfur clusters, either-cysteine coordinated $[4 \mathrm{Fe}-4 \mathrm{~S}]$ or $[2 \mathrm{Fe}-4 \mathrm{~S}]$ structures, that serve as conduits between catalytic metal sites and external electron donors/acceptors. Native or genetically modified whole cells of hydrogenase-containing $E$. coli have also been employed as biocatalysts for hydrogen production $[48,49]$.

In suspended photocatalytic systems, the complexity of their design is largely dependent on the semiconductors employed. For example, in order to operate in the visible light, $\mathrm{TiO}_{2}$ requires photosensitization by synthetic dyes which, in turn, often require the use of sacrificial electron donors for regeneration. In contrast, semiconductors such as CdS and CdTe absorb visible light and can be readily employed without the need of using a photosensitizer. Similarly, mediators as methyl viologen can be used to facilitate electron transfer between enzymes and semiconductors, although that need is obviated in systems wherein enzymes are directly immobilized onto semiconductor surfaces.

Among the earliest examples of the integration of such an enzyme with semiconductors was the coupling of hydrogenase to anatase $\mathrm{TiO}_{2}$ in the 1980 s $[50,51]$. Hydrogen evolution was achieved through direct adsorption of hydrogenase on $\mathrm{TiO}_{2}$ in one study and, in separate work, via viologen-mediated electron transfer by rhodium complexes using EDTA or methanol as a sacrificial electron donor. Subsequent work using [NiFe]-hydrogenase in conjunction with 
$\mathrm{TiO}_{2}$ and $\mathrm{CdS}$ was reported [52-55]. Additionally Armstrong and co-workers successfully employed $\mathrm{TiO}_{2}$, sensitized with $\left[\mathrm{Ru}^{\mathrm{II}}(\mathrm{bpy})_{2}\left(4,4^{\prime}-\left(\mathrm{PO}_{3} \mathrm{H}_{2}\right)_{2}-\mathrm{bpy}\right)\right]^{2+}(\mathrm{RuP})$, along with immobilized [NiFeSe]-hydrogenase to photolytically drive hydrogen production using TEOA as a sacrificial electron donor (Figure 2a) $[56,57]$. Their study demonstrated that [NiFeSe]hydrogenase has better performance than [FeFe]-hydrogenases and [NiFe]-hydrogenases [58]. Apparently replacing one cysteine ligand to the nickel ion by selenocysteine results in higher oxygen tolerance with the retention of high hydrogen production activity [47].

(a)

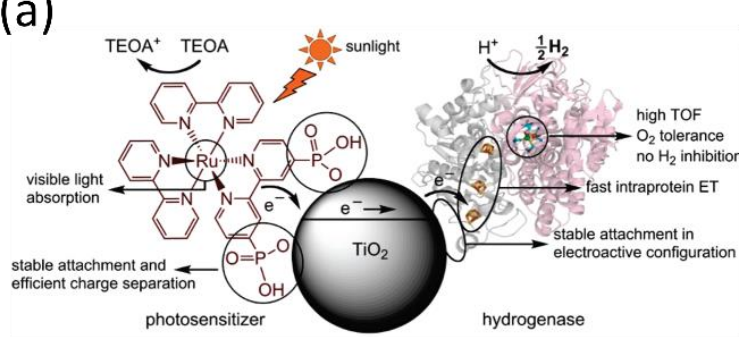

(c)

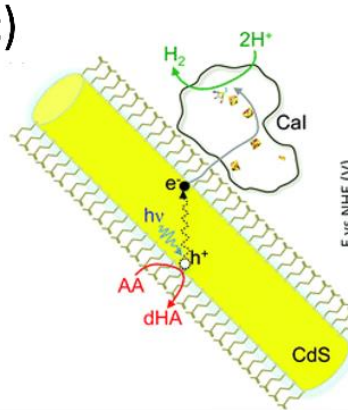

(b)

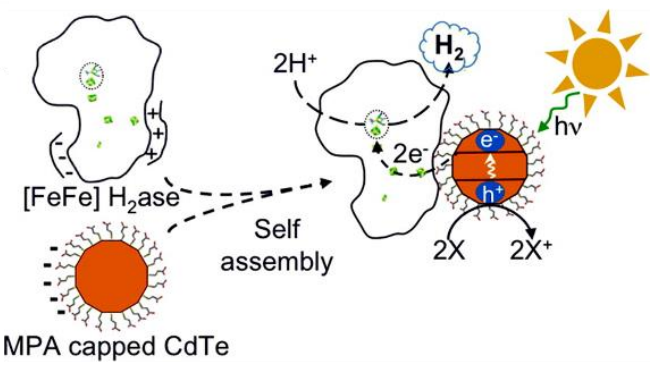

(d)

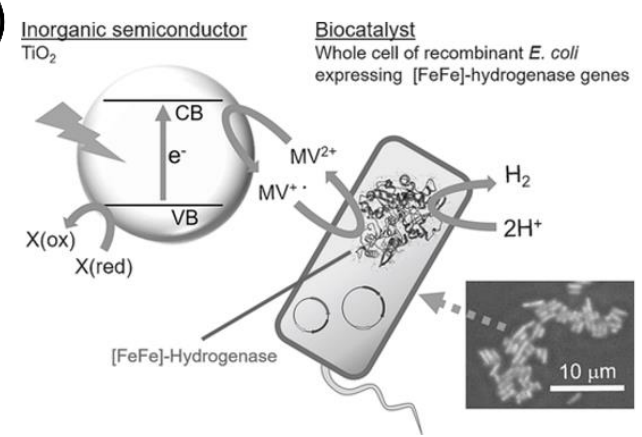

Figure 2 Examples of semiconductor-biohybrid systems for hydrogen evolution with hydrogenases immobilised on (a) $\mathrm{TiO}_{2}$ nanoparticles sensitized with RuP dye [57] (Reproduced with permission from American Chemical Society), (b) CdTe nanoparticles capped with 3mercaptopropionic acid (MPA) [59] (Reproduced with permission from American Chemical Society), (c) CdS nanorods capped with MPA [60] (Reproduced with permission from American Chemical Society). (d) The whole cell of recombinant E. Coli express [FeFe]hydrogenase genes immobilised on $\mathrm{TiO}_{2}$ [48] (Reproduced with permission from John Wiley and Son). 
Metal chalcogenides such as CdTe and CdS, which have bandgaps corresponding to visible light, offer the advantage of a simplified hybrid design because there is no need of a photosensitizer. Brown et. al. reported successful solar hydrogen production using hydrogenase immobilized to CdTe nanoparticles capped with 3-mercaptopropionic acid (Figure 2b), a structure that afforded stable enzyme complexes owing to strong electrostatic interactions [59]. Their subsequent studies with [FeFe]-hydrogenase adsorbed on $\mathrm{CdS}$ nanorods (Figure 2c) employed the same strategy and achieved turnover frequencies of 380 to $900 \mathrm{~s}^{-1}$ in hydrogen evolution, among the highest yet reported [60]. This result highlights the importance of semiconductor dimensionality; compared to 0D nanoparticles, 1D nanorod structures promote directional charge transfer and thereby enhance photocatalytic performance. Interestingly, they later reported that overall photoreduction activity was found to be dependent on design considerations; specifically, the kinetics of electron injection from nanocrystal $\mathrm{CdS}$ to the active site of [FeFe]-hydrogenase [61] was controllable by the length of the ligands, with the use of shorter linkages resulting in enhanced efficiency [62]. This exemplifies the more general concept that semiconductor architecture effects catalytic performance of such hybrid systems: optimal interfacial properties between enzymes and semiconductors are critical for the efficient electron transfer from the semiconductors to the active sites of enzymes and greatly affect the rates of catalytic reactions.

The application of whole cells to the hybrid system, instead of purified hydrogenases, is another interesting approach that offers an advantage of avoiding the laborious and costly purification steps to isolate these enzymes from their native organisms. Such strategies have been reported by several researchers [63-65]. Recently, Honda et. al. [48]. directly employed whole cells of recombinant $E$. Coli (combinant strain of $E$. Coli expressing the genes encoding the $[\mathrm{Fe}-\mathrm{Fe}]$-hydrogenase and relevant maturases) as a biocatalyst for hydrogen production (Figure 2d). The combination of $\mathrm{TiO}_{2}$, a whole cell of recombinant E. Coli, and methyl 
viologen as an electron mediator, achieved photocatalytic hydrogen production, but at an apparent quantum yield at $300 \mathrm{~nm}\left(\mathrm{AQY}_{300}\right)$ of only $0.3 \%$. However, the whole cell biocatalyst was found to have greater stability than systems using only the purified enzymes. By finding optimal conditions to facilitate methyl viologen reduction, they further improved the photocatalytic hydrogen productivity of $\mathrm{AQY}_{300}$ to $26.4 \%$, a nearly 90 -fold increase [66].

An emerging approach in the application of whole cells is by self-precipitated semiconductor on bacteria for photocatalytic biohydrogen production. Yang and coworkers pioneered this approach when they induced formation of CdS nanoparticles on the surface of a nonphotosynthetic bacterium, Moorella thermoacetica, to promote the reduction of $\mathrm{CO}_{2}$ [67]. The details of this mediatorless system are discussed below in the section on photocatalytic $\mathrm{CO}_{2}$ reduction. By applying the same concept, Wong and co-workers reported enhanced hydrogen production on nonphototrophonic E. coli by photogenerated electrons from surfaceprecipitated CdS nanoparticles (Figure 3a) [49]. The apparent quantum efficiencies of the hybrid system under 470 and $620 \mathrm{~nm}$ visible light irradiation were $7.93 \%$ and $9.59 \%$, respectively. In their follow-up work $A g \ln S_{2} / \operatorname{In}_{2} S_{3}$ was precipitated on E. coli. for biological $\mathrm{H}_{2}$ production (Figure $3 b$ ) [68]. $\mathrm{In}_{2} \mathrm{~S}_{3}$ nanoparticles were biologically grown on the surface of E. coli by the addition of suitable amount of $\mathrm{In}^{3+}$ and cysteine, followed by anchoring of $\mathrm{Ag} \ln \mathrm{S}_{2}$ nanoparticles on the surface of $\operatorname{In}_{2} \mathrm{~S}_{3}$ via an in-situ ion exchange. This $A g \ln \mathrm{S}_{2} / \operatorname{In}_{2} \mathrm{~S}_{3}-E$. coli hybrid system had a reported quantum efficiency of $3.3 \%$ at $720 \mathrm{~nm}$ for $\mathrm{H}_{2}$ production, which the authors claimed exceeded those of many photoheterotrophic bacteria.

In other recent work, Zhao and coworkers reported a strategy by engineering of $E$. coli cells through in situ biosynthesis of CdS nanoparticles using a surface-displayed heavy metalbinding proteins (Figure 3c) [69]. A biomimetic silica encapsulation strategy was introduced into the engineered $E$. coli cells that contained oxygen-sensitive [NiFe]-hydrogenase; the silica 
serves as a shell to exclude oxygen, enabling this hybrid system to continuously produce hydrogen for 96 hours under natural aerobic conditions.

(a)

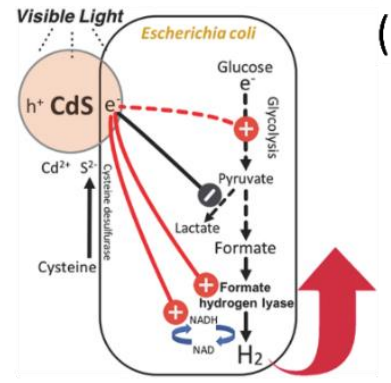

(b)

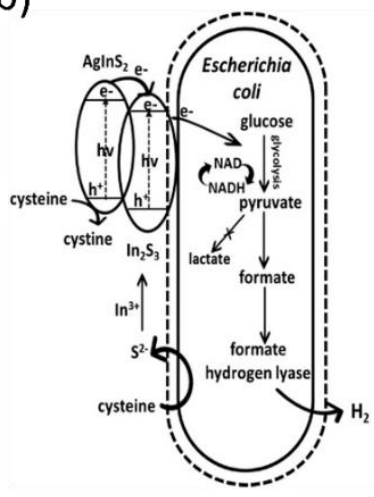

(c)

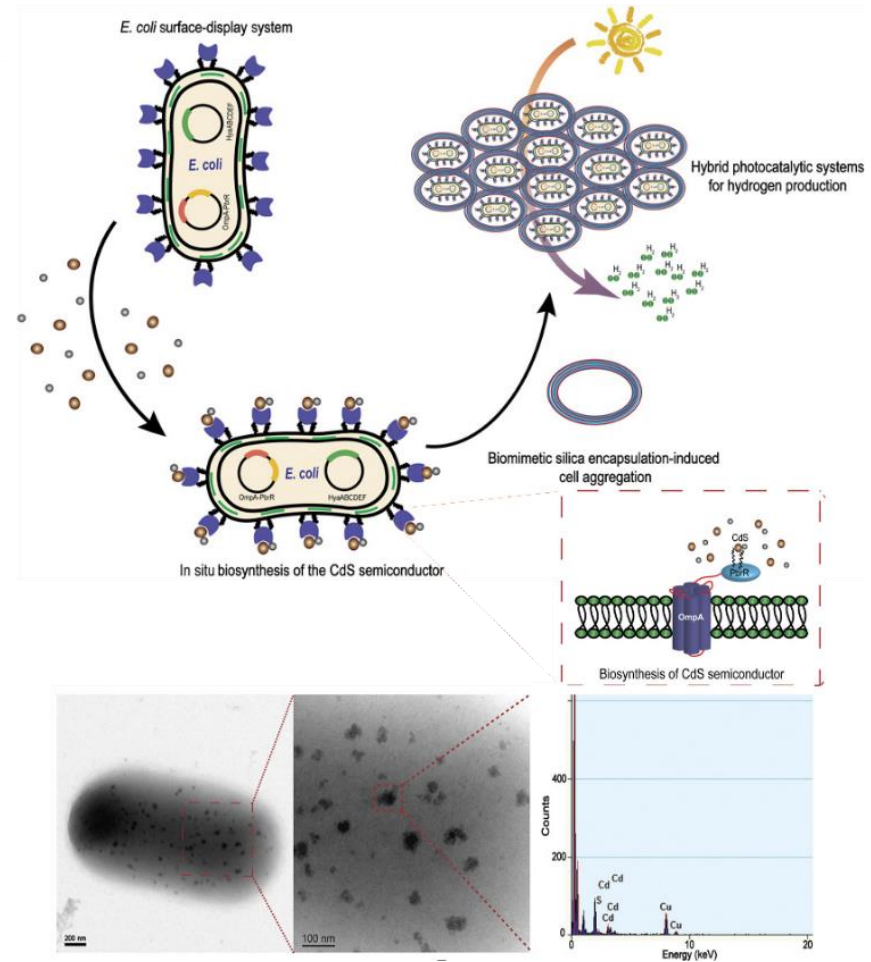

Figure 3 Strategies for enhanced hydrogen evolution in hybrid system with precipitation of semiconductors on E. Coli, with (a) CdS [49] (Reproduced with permisson from John Wiley and Son), and (b) $A g \operatorname{InS}_{2} / \operatorname{In}_{2} \mathrm{~S}_{3}$ [68] (Reproduced with permisison from Elsevier). (c) Top: Illustration of surface-display biohybrid approach in solar-driven hydrogen production in air. Bottom: TEM images of biosynthesized CdS nanoparticles on the surface of an engineered $E$. coli cell, as well as EDX confirmation of CdS [69] . (Reproduced with permission from John Wiley and Son). 


\subsection{Enzymatic photocatalytic $\mathrm{CO}_{2}$ reduction}

Direct reduction of carbon dioxide can be achieved by a number of enzymes and is an area of active research. Carbon monoxide dehydrogenases (CODH) and formate dehydrogenase $(\mathrm{FDH})$ are specific and selective enzymes in reducing $\mathrm{CO}_{2}$ to $\mathrm{CO}$ and formate, respectively. The former consists of two major classes, [Ni4Fe-4S] and Mo-[2Fe-2S]-FAD active site containing CODH enzymes [70-73]. Both classes of CODHs catalyze the reversible conversion between $\mathrm{CO}_{2}$ and $\mathrm{CO}$ via iron-sulfur clusters $\left(\mathrm{Fe}_{4} \mathrm{~S}_{4}\right)$. FDHs with tungsten and molybdenum active sites are capable of direct reversible conversion of $\mathrm{CO}_{2}$ and formate [7477]. In contrast, another class of metal-independent FDHs requires the use of an unstable and expensive nicotinamide adenine dinucleotide (NADH) to reduce $\mathrm{CO}_{2}[78-80] . \mathrm{CO}_{2}$ can also be reduced to acetic acid by acetogens, anaerobic whole cell bacteria, via the Wood-Ljungdahl pathway [81]. M. thermoacetica has been the model organism for this work, which includes genetic engineering to generate products of industrial interest, such as acetone and butanol [82].

The seminal work by Parkinson and Weaver in 1984 demonstrated photoelectrochemical reduction of $\mathrm{CO}_{2}$ to formic acid with $\mathrm{FDH}$ immobilized on a $p$-type indium phosphide semiconductor [83]. Thus, the strategies described in the previous section to integrate hydrogenases in semiconductor electrodes are relevant for enzymes with $\mathrm{CO}_{2}$ reduction functionality. For example, $\mathrm{CODH}$ immobilized on ruthenium-sensitised $\mathrm{TiO}_{2}$ (Figure 4a) was found to selectively convert $\mathrm{CO}_{2}$ to $\mathrm{CO}$ with a TOF of $\sim 0.18 \mathrm{~s}^{-1}[71,84]$. A recent study by Armstrong and co-workers demonstrated that silver nanoclusters stabilized by polymethacrylic acid (AgNCs-PMAA) effectively serve as a photosensitizer toward $\mathrm{TiO}_{2}$ bound CODH, achieving a TOF of $20 \mathrm{~s}^{-1}$ under visible light illumination (Figure 4b) [85]. They proposed that the AgNCs-PMAA coating facilitate dynamic interaction of the Ag nanoclusters with the CODH surface, potentially at the exposed cysteine thiols. Strong coupling of the Ag nanoclusters on $\mathrm{TiO}_{2}$ also facilitates the electron transfer requires for $\mathrm{CO}_{2}$ reduction catalytic 
on CODH. This strategy illustrates the potential of enhancing the efficiency of hybrid semiconductor-photosensitizer/enzyme systems by increasing the flux of photo-generated mobile electrons. As mentioned previously the use of visible-light driven semiconductors obviates the need for a photosensitizer. In one such system using CdS (Figure 4c), the photocatalytic conversion of $\mathrm{CO}_{2}$ to $\mathrm{CO}$ on $\mathrm{CODH}$ was found to depend on the size and shape of the semiconductor particles. Specifically, CODH immobilized on CdS nanorods exhibited average TOF of $1.23 \mathrm{~s}^{-1}$, compared to $0.25 \mathrm{~s}^{-1}$ observed for the enzyme on CdS quantum dots [72]. This data is consistent with studies on hydrogenase-CdS systems, in which 1D nanorods were shown to enhance photo-generated charge carrier separation. 
(a)

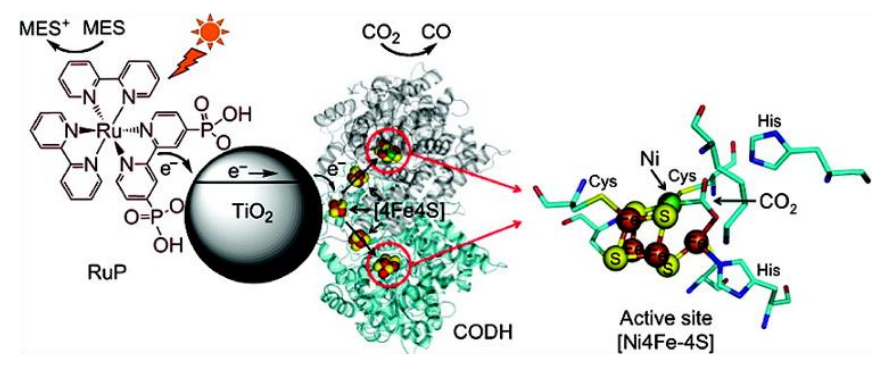

(b)

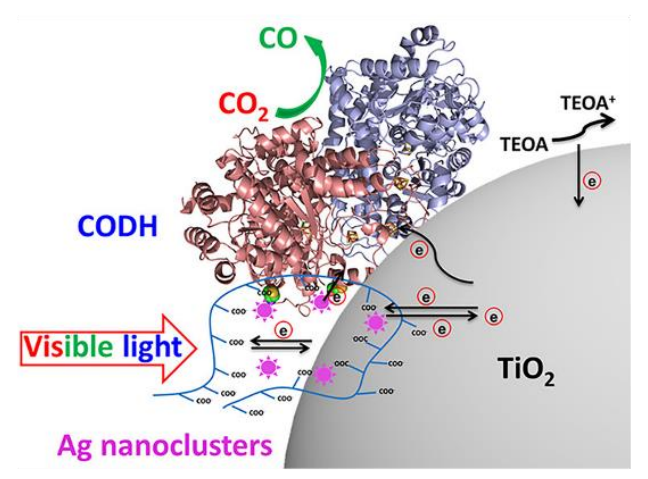

(c)

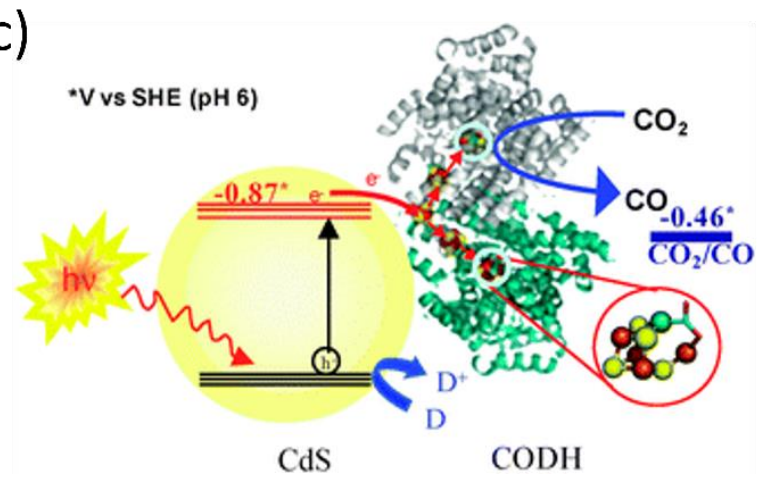

Figure 4 Examples of semiconductor-biohybrid systems for $\mathrm{CO}_{2}$ reduction to $\mathrm{CO}$ with $\mathrm{CODH}$ immobilised on (a) $\mathrm{TiO}_{2}$ nanoparticles sensitized with $\mathrm{RuP}$ dye [71] (Reproduced with permission from American Chemical Society), (b) $\mathrm{TiO}_{2}$ nanoparticles sensitized with silver nanoclusters stabilized by polymethacrylic acid [85] (Reproduced with permission from American Chemical Society), and (c) CdS nanorods [72] (Reproduced with permission from Royal Society Chemistry). 
(a)

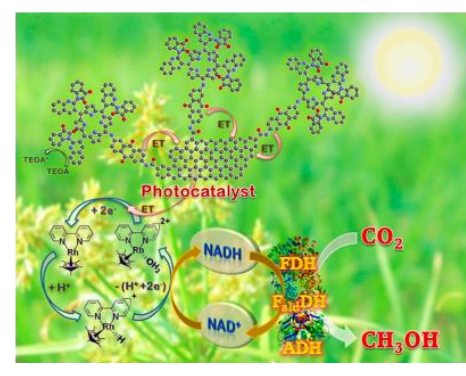

(b)

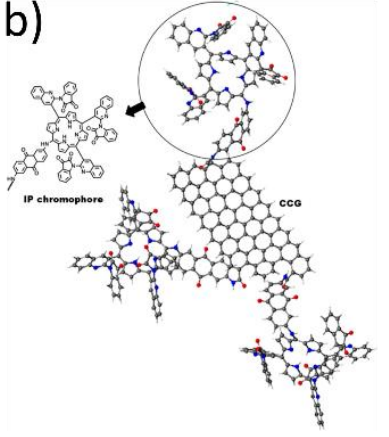

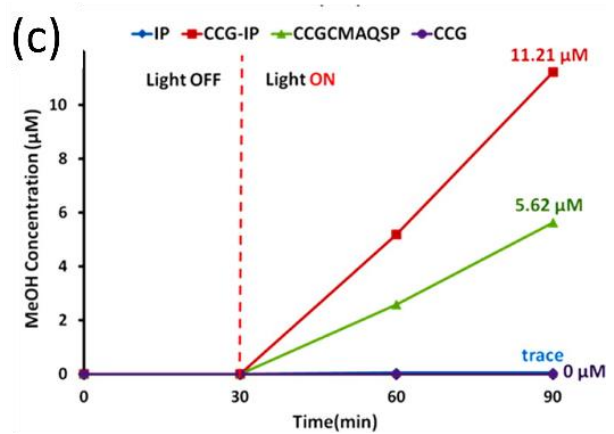

Figure 5 (a) Illustration of the chemically converted graphene (CCG)- with combination of two chromophoric motifs, isatin and porphyrin (denoted as IP) integrated with FDH $=$ formate dehydrogenase, $\mathrm{F}_{\text {ald }} \mathrm{DH}=$ formaldehyde dehydrogenase, and $\mathrm{ADH}=$ alcohol dehydrogenase for $\mathrm{CO}_{2}$ reduction to methanol. (b) $3 \mathrm{D}$ structure of CCG-IP photocatalyst with detailed chemical structure of IP chromophore. (c) Comparison of CCGCMAQSP photocatalyst, with IP-CCG, with the latter exhibiting enhanced performance. (From [86], reproduced with permission from American Chemical Society).

Graphene-based 2D nanosheets have also been used as photocatalysts in hybrid $\mathrm{CO}_{2}$ reduction systems that utilize visible light. In one such system reported by Baeg and coworkers [87], the chromophore, a multi-anthraquinone substituted porphyrin, was covalently bound to chemically modified graphene (CCGCMAQSP); integration with an NADH regeneration enzyme afforded $\mathrm{CO}_{2}$ reduction to formic acid using a rhodium complex as a mediator. The same group introduced a more complex system by combination of two highly versatile chromophoric motifs, isatin and porphyrin, to achieve improved visible light harvesting, enabling efficient regeneration of enzymatically active NADH (Figure 5) [86]. Interestingly, the authors successfully used this system to selectively and photocatalytically reduce $\mathrm{CO}_{2}$ to methanol via the sequential coupling of three enzymes: formate dehydrogenase, formaldehyde dehydrogenase, and alcohol dehydrogenase [86]. 

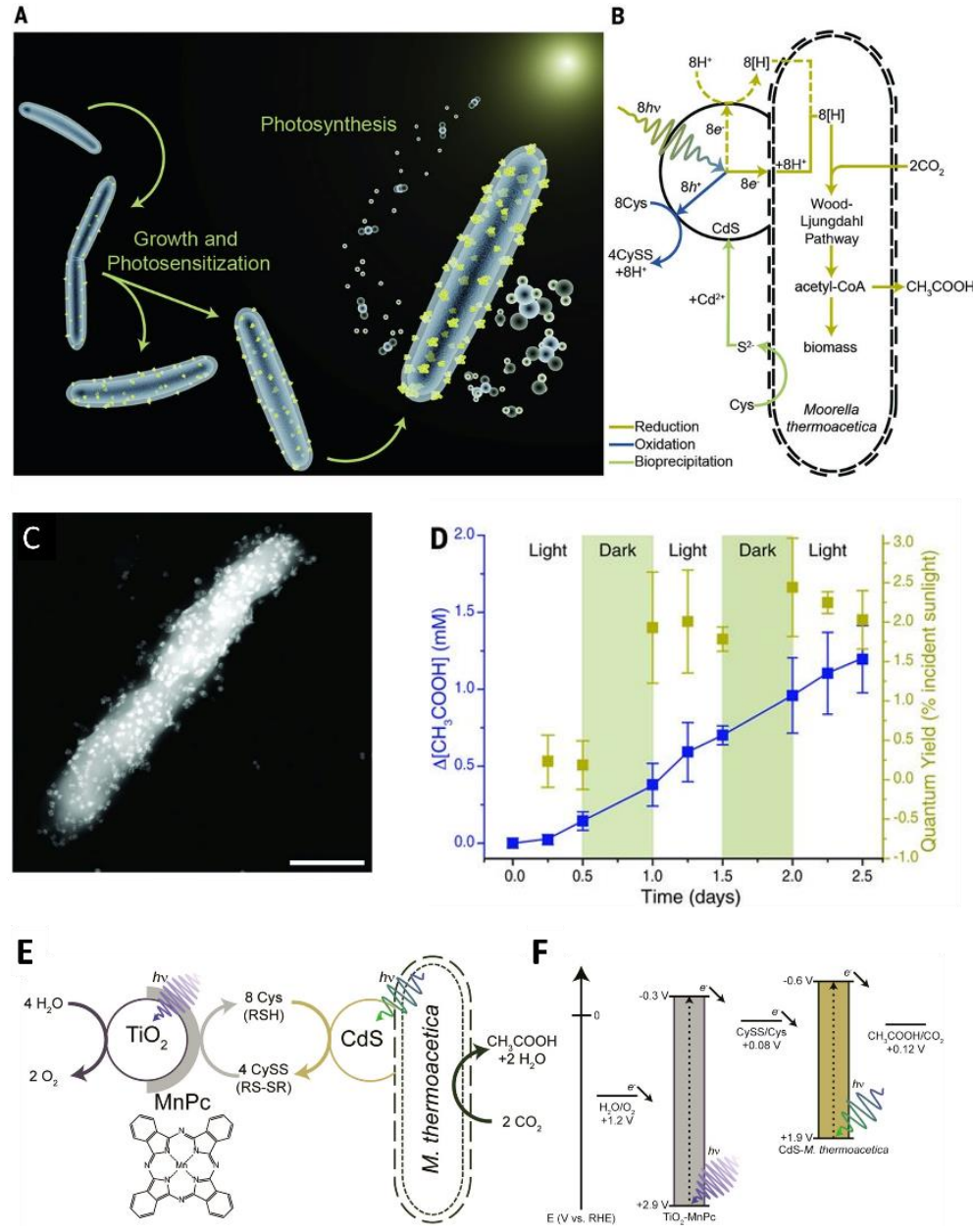

Figure 6 (a) Illustration of $M$. thermoacetica - CdS hybrid system involving the bioprecipitation of $\mathrm{CdS}$ nanoparticles and the photoreduction of $\mathrm{CO}_{2}$ to acetic acid. (b) Energy and mass balance of the $M$. thermoacetica - CdS system involved in the reduction of $\mathrm{CO}_{2}$ to acetic acid. (c) High-angle annular dark field (HAADF) STEM image of a single cell, showing CdS clusters across the entire cell surface. Scale bar $=500 \mathrm{~nm}$. (d) Dark-light cycles of acetic acid production under low-intensity simulated sunlight. (a to d, From [67], Reproduced with permission from American Association for the Advancement of Science). (e) The $M$. thermoacetica $-\mathrm{CdS}+\mathrm{TiO}_{2}-\mathrm{MnPc}$ tandem system, where co-illumination of $\mathrm{TiO}_{2}-\mathrm{MnPc}$ drives the reduction of CySS back into Cys, coupled to oxidation of water to $\mathrm{H}_{2} \mathrm{O}$. (f) Energy level diagram depicting suitable thermodynamic levels of the $\mathrm{TiO}_{2}$ and $\mathrm{CdS}$ (e to f, From [88], Reproduced with permission from American Chemical Society). 
While most hybrid systems utilize isolated enzymes immobilised on photocatalytic materials for $\mathrm{CO}_{2}$ photoreduction, Yang and coworkers employed the reverse strategy, precipitating $\mathrm{CdS}$ nanoparticles on an acetogen microorganism, $M$. thermoacetica (Figures 6ad) [67]. This class of whole cell bacteria is capable of directly extracting electrons from a solid electrode [89]; In this case, photogenerated electrons from illuminated CdS are transferred to M. thermoacetica, ultimately reducing $\mathrm{CO}_{2}$ to acetic acid. Because living bacteria were utilized in this syetm, instead of isolated enzymes, self-photosensitization and self-replication were demonstrated. Acetic acid was shown to be continuously produced over several days of lightdark cycles, with an overall quantum efficiency of about $2 \%$ for the first day under low intensity simulated sunlight. To overcome the otherwise irreversible oxidation of cysteine (Cys) to cystine (CySS) in this system, a tandem Z-scheme approach was devised, employing a photocatalytic reaction of $\mathrm{TiO}_{2}-\mathrm{Mn}(\mathrm{II})$ phthalocyanine $(\mathrm{MnPc})$, to regenerate the $\mathrm{CySS} / \mathrm{Cys}$ redox shuttle (Figures 6e-f) [88]. More recently, they achieved a quantum efficiency of $2.86 \pm$ $0.38 \%$, higher than their earlier work on biohybrid of $M$. thermoacetica - CdS system, by binding gold nanoclusters to $M$. thermoacetica using the naturally occurring peptide glutathione (Au22(SG)18) [90].

\subsection{Hybrid semiconductor-bioinorganic photoelectrochemical system}

For the hybrid photocatalytic systems described in the previous sections, the nanostructured semiconducting materials with surface-immobilized enzymes are in the form of suspensions. An attractive alternative approach involves immobilising enzymes directly on conductive support electrodes $[41,91-93]$. This has several potential advantages. Apart from obviating the need for sacrificial reagents, an applied external bias potential could modulate the catalytic reactions. Furthermore, useful information such as faradaic efficiencies could be 
readily obtained. The approach also offers the possibility of designing a compartmentalized assembly of desirable anodic and cathodic reaction. Finally, if the electrodes are made of semiconducting materials, light-driven photoelectrochemical oxidation or reduction reactions are possible. We review below two types of electrodes, categorised as conventional and advanced. They serve the same purpose in enzyme-based co-catalyst immobilization photoelectrodes, but the latter have 3D hierarchical structures which allows for enhanced enzyme loading, and may also offer enzymatic protection through the formation of anaerobic regions within their hierarchical structures.

\subsection{Conventional electrode architectures}

Carbon-based electrode materials are promising substrates for the deposition of protein or enzyme films [94]. Edge-plane pyrolytic graphite is particularly well-suited as it possesses various aromatic, hydrophilic, and carboxylate functionalities, present as defects on the edge plane, which stabilize enzyme interactions $[94,95]$. Other high surface area carbon materials, such as carbon felt, carbon cloth, and carbon nanotube arrays, have also been employed to enhance enzyme loading in systems that require high current densities [96-98]. In addition, metallic gold electrodes are commonly functionalised to allow specific interactions with enzymes [92, 93, 99]. All of these options, however, have limited application for direct photocatalytic application owing to their optical properties.

In contrast to the above, bulk $\mathrm{TiO}_{2}$ has been shown to have exceptional affinity for hydrogenase immobilisation [100]. Excellent adsorption of hydrogenases on $\mathrm{TiO}_{2}$ electrodes allow for electrocatalytic $\mathrm{H}_{2}$ evolution with almost unity faradaic efficiency, as well as excellent long-term stability [101]. This nonspecific adsorption could be facilitated by immobilisation steps performed at isoelectric $\mathrm{pH}$ points, allowing for some degree of control of the electrostatic interactions between the enzymes and $\mathrm{TiO}_{2}$ [102]. However, 
photoelectrochemical $\mathrm{H}^{+}$and $\mathrm{CO}_{2}$ reductive reactions are only thermodynamically feasible on p-type semiconductors that possesses suitable conduction bands potentials.

(a)

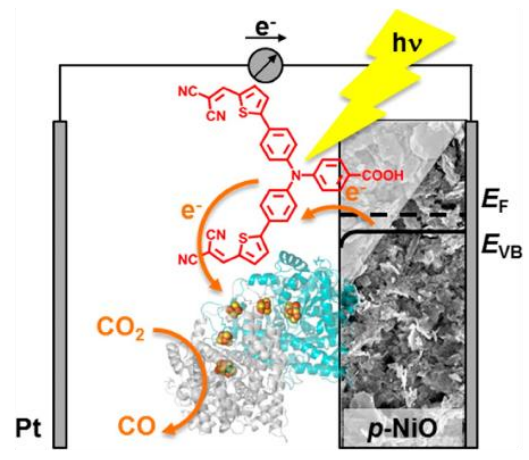

(c)

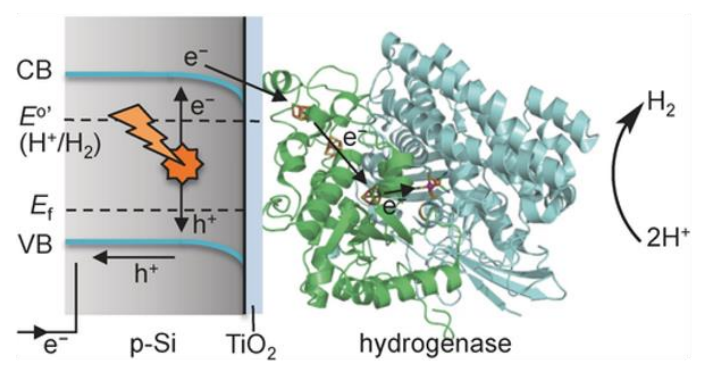

(b)

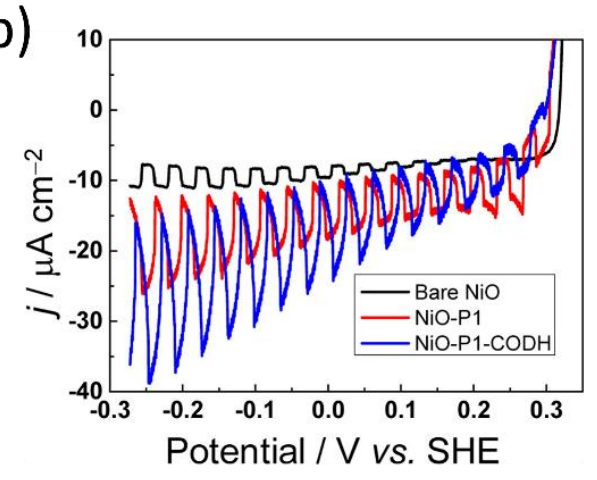

(d)

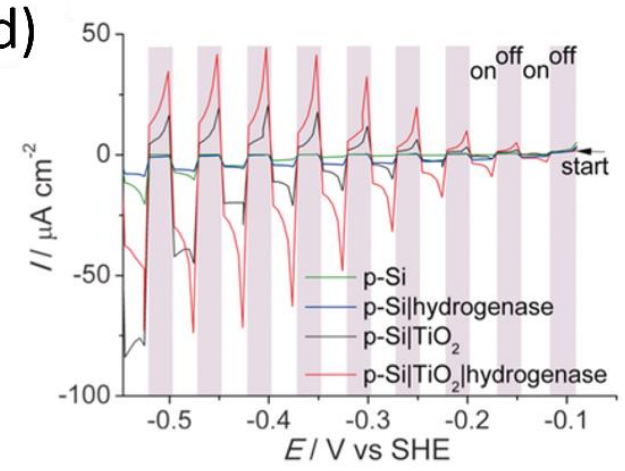

Figure 7 Examples of photoelectrochemical systems with (a) dye-sensited $p$-NiO-CODH for $\mathrm{CO}_{2}$ reduction to $\mathrm{CO}$, and the corresponding photoelectrochemical responses (b) [103]

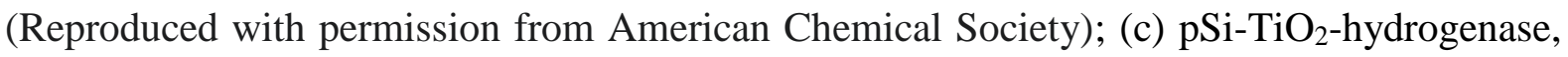
and the corresponding photoelectrochemical responses (d) [104] (Reproduced with permission from John Wiley and Son).

Based on p-type $\mathrm{NiO}$ electrodes developed by Sun and coworkers for dye sensitized solar cells and photo-driven hydrogen production $[105,106]$, Bachmeier et. al. reported that CODH immobilized on a dye-sensitized porous $\mathrm{NiO}$ cathode facilitated selective $\mathrm{CO}_{2}$ reduction to $\mathrm{CO}$ (Figure 7a-b) [103]. Although the system was relatively stable under electrocatalytic condition, $\mathrm{NiO}$ is not considered to be highly efficient photoelectrocatalytic electrode material. $\mathrm{p}$-Si, on 
the other hand, is considered to be the most efficient p-type semiconductor. However, p-Si is atomically flat and smooth, making enzyme immobilisation with sufficient loading and stability a challenge. To address this, Reisner and co-workers introduced a thin amorphous layer of $\mathrm{TiO}_{2}$ to promote adhesion of hydrogenases to the electrode surface. Favourable adsorption of hydrogenases on $\mathrm{TiO}_{2}$ further facilitates the proton reduction to hydrogen in this system (Figure 7c-d) [104]. In related work, Zhao et. al. used nanoporous black Si allows directly bound to [FeFe]-hydrogenase; this system exhibited excellent performance with an overpotential $280 \mathrm{mV}$ lower than that observed with bare Si [107]. In this system, higher photoelectrochemical current was obtained compared to the $\mathrm{TiO}_{2}$-modified system. Generally, hybrid systems based on conventional electrodes are limited with respect to their loading capacity of enzyme and their long-term stability under turnover conditions. 


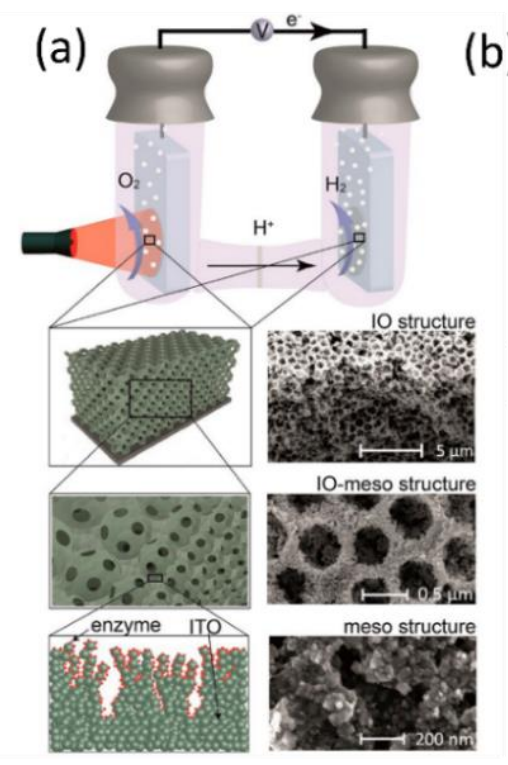

(b)
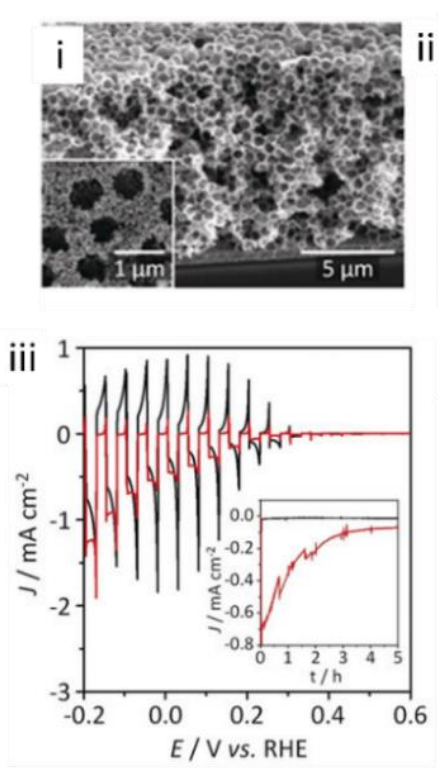
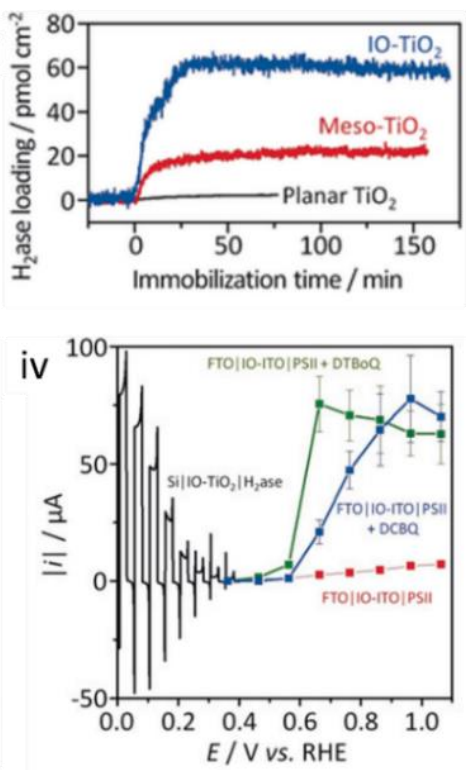

Figure 8 (a) The photoelectrochemical water splitting system with enzymes immobilized on IO-ITO; FTO IO-ITO | PSII served as an anode, and FTO | IO-ITO | hydrogenase as an anode [108] (Reproduced with permission from American Chemical Society). (b) SEM image of p$\mathrm{Si}-\mathrm{IO}_{-} \mathrm{TiO}_{2}$ (i) and comparison of hydrogenase loading capability between IO-, meso- and planar $\mathrm{TiO}_{2}$ (ii), Photoelectrochemical proton reduction of p-Si | IO-ITO | hydrogenase (iii) [109] (Reproduced with permission from John Wiley and Son), and (iv) Tandem photoelectrochemical water splitting with p-Si | IO-ITO | hydrogenase as a cathode, and FTO| IO-ITO | PSII as an anode [110] (Reproduced with permission from Springer Nature).

The inverse-opal (IO) structure of indium tin oxide (ITO), developed by Reisner and coworkers, is a relatively new and particularly promising $3 \mathrm{D}$ electromaterial for enzyme immobilization [108]. They introduced this new electrode material for enzyme loading in their initial demonstration of coupling photosystem II to hydrogenases for photoelectrochemical water splitting (Figure 8a). As ITO is transparent, it meets the criteria of light penetration and 
absorption and is therefore suitable for light-driven enzymatic reactions such as those involving PSII. In comparison to meso-ITO [111], the hierarchical inverse opal structure with microporous architecture not only enhances enzyme loading, but also allows efficient reactant and product diffusion. In this system, quantification of the oxygen and hydrogen products in the anodic and cathodic compartments, respectively, revealed a light-to-hydrogen conversion efficiency of $5.4 \%$ at $680 \mathrm{~nm}[108]$.

Using the same IO structure but with $\mathrm{TiO}_{2}$ materials $\left(\mathrm{IO}-\mathrm{TiO}_{2}\right)$, high hydrogenase loading was achieved (Figure 8bi-ii). This $\mathrm{IO}^{-} \mathrm{TiO}_{2}$ electrode was fabricated on an atomic layer deposition (ALD) protected p-Si and subsequent loading of hydrogenase yielded p-Si|IO$\mathrm{TiO}_{2}$ |hydrogenase for photoelectrochemical proton reduction [109]. Via this strategy, substantially greater hydrogenase immobilization was afforded, yielding correspondingly higher photoelectrochemical currents compared to earlier work with hydrogenase loaded on ptype silicon coated with a thin layer of amorphous $\mathrm{TiO}_{2}$. The assembly of a tandem photoelectrochemical water splitting cell was made possible by coupling the p-Si|IO$\mathrm{TiO}_{2} \mid$ hydrogenase cathode to an FTO-IO-PSII photoanode (Figure 8b-iii). A bias free enzymebased photoelectrochemical water splitting cell was successfully constructed by employing a similar design (Figure 8b-iv), except with a dye-sensitized FTO-IO-PSII photoanode that broadened the range of wavelengths absorbed [110]. It is worth noting that such hierarchical IO structures hold promise not only for the development of electrochemical devices, but have also assisted in fundamental mechanistic investigations of PSII $[38,112]$. The IO-ITO structure also served as an effective platform to study protein-enzyme interactions in which decahaem cytochrome MtrC from Shewanella oneidensis MR-1 served as a protein electron conduit to tune the electrocatalytic reactions of hydrogenase and fumarate reductase [113]. Another multiprotein system constructed on IO-ITO involved photosystem 1, cytochrome c and human sulfite oxidase, has been used for light-driven biocatalytic sensing [114]. 

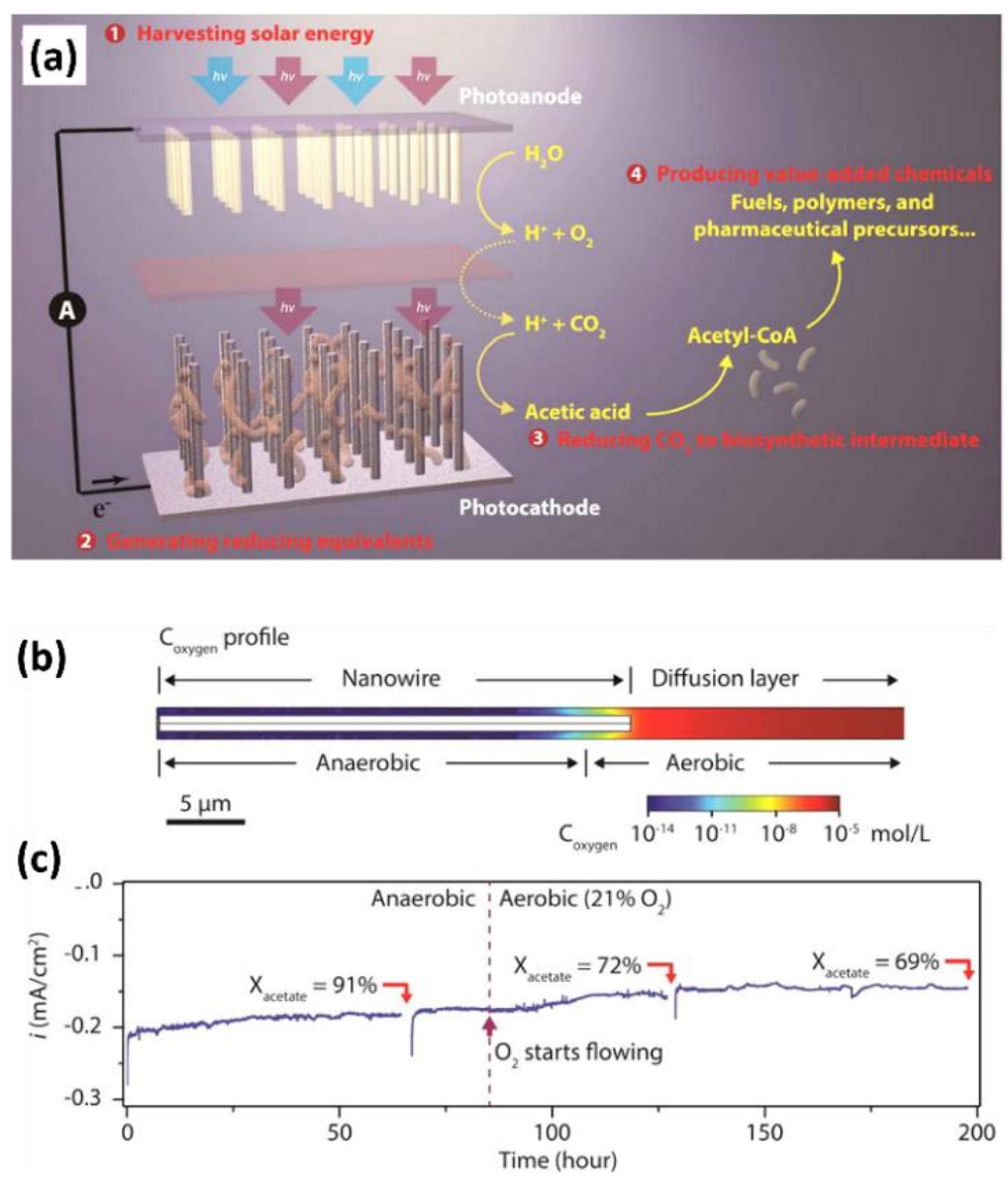

Figure 9 (a) A hybrid silicon nanowire/bacteria system for solar-driven $\mathrm{CO}_{2}$ fixation. (b) Simulation of enhanced oxygen tolerance for nanowire-bacteria hybrids shows $\mathrm{O}_{2}$ concentration in the electrolyte decreases logarithmically from the nanowire array entrance, creating a local anaerobic environment that allows for the survival of $S$. ovata in an otherwise aerobic environment; (c) Experimental demonstration of $\mathrm{CO}_{2}$ reduction by $S$. ovata under aerobic conditions when Pt was additionally loaded onto the nanowire electrode [115] (Reproduced with permission from American Chemical Society).

Yang and coworkers reported the photoelectrochemical reduction of $\mathrm{CO}_{2}$ to acetic acid under aerobic conditions $\left(21 \% \mathrm{O}_{2}\right)$ using an assembly of a 3D biocompatible silicon nanowire 
array interfacing with a living anaerobic bacterium, Sporomusa ovata (Figure 9); the system operated at a low overpotential $(\eta<200 \mathrm{mV})$ and was stable up to $200 \mathrm{~h}$ under simulated sunlight, exhibiting energy-conversion efficiency of up to $0.38 \%$ [115]. The hierarchical nanowire array structure not only enhanced the cell loading of $S$. ovata in comparison to a planar Si electrode, but also allowed the generation of a local anaerobic environment at the bottom of the nanowire arrays that made the catalytic conversion possible in an aerobic bulk environment. The system is operable without applying external bias potential, with $\mathrm{TiO}_{2}$ nanowires serving as a photoanode, providing electrons to effect $\mathrm{CO}_{2}$ reduction. By employing genetically engineered $E$. coli strains, the resulting acetate can be activated to acetyl coenzyme A, making possible the synthesis of a variety of value-added chemicals, such as n-butanol, polyhydroxybutyrate polymer, and isoprenoid natural products.

\subsection{Other functional 3D architectures in photocatalytic systems}

Many examples of photocatalytic systems for $\mathrm{H}_{2}$ evolution and $\mathrm{CO}_{2}$ reduction have been reported that employ hierarchical 3D structures of various inorganic semiconductors [116124]. Within the context of this review, we have selected a few 3D architecture fabrication strategies that are relevant to, or could be applicable to, future studies on hybrid enzymatic bioinorganic systems. For example, 3D architectures, fabricated from nanoporous glass structures, offer favourable anaerobic environment for hydrogenase and prevent catalytic deactivation under aerobic conditions. Emerging 3D printing approaches in the fabrication of 3D photocatalytic materials with desirable patterned structures are described and, finally, the design of 3D architectures from 2D nanosheets is presented. 


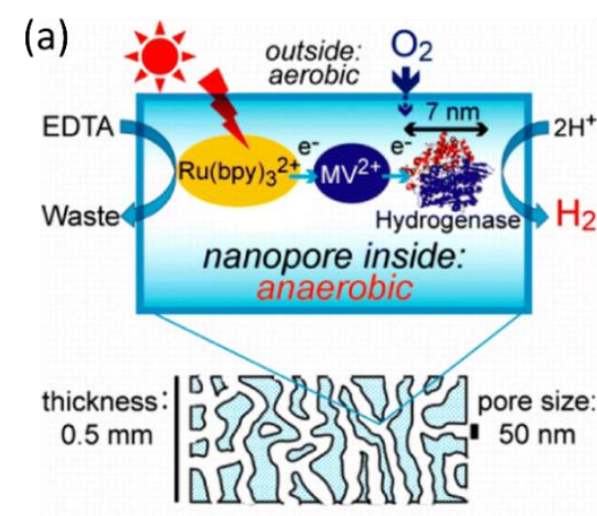

Porous Glass Plate

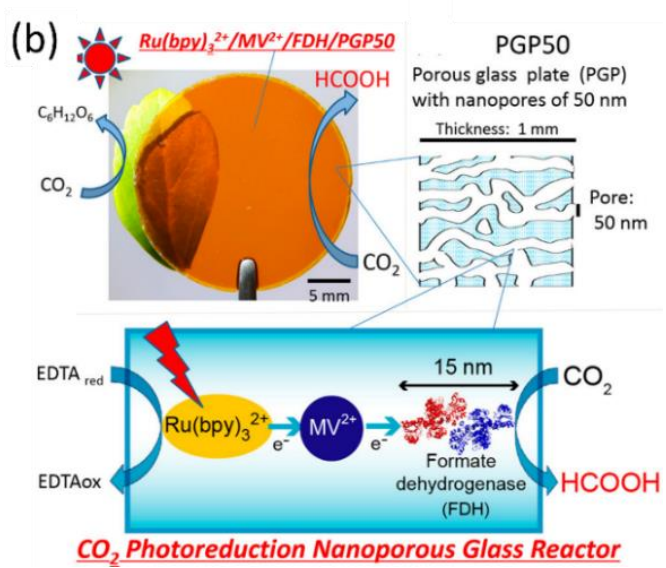

Figure 10 Light-induced hydrogen (a) and formic acid (b) productions in nanopores glass plate incorporation with $\mathrm{Ru}(\mathrm{bpy})_{3}{ }^{2+} / \mathrm{MV}^{2+} /$ enzyme. The enzymes employed were hydrogenase and formate dehydrogenase, respectively. [125, 126] (Reproduced with permission from American Chemical Society).

Routine use of hydrogenases is complicated by the fact that most of them are extremely oxygen sensitive and prone to deactivation under aerobic conditions. While bioengineering of hydrogenase mutants may enhance resistance to degradation by oxygen, it is a laborious and costly process. Alternatively, Plumeré et. al. developed a chemically-based strategy using a viologen-based redox hydrogel; this protects hydrogenases from oxygen-induce damage as well as deactivation under electrocatalytic conditions from excessively high applied potentials [127]. Noji et. al. used an entirely different approach to protect hydrogenases (Figure 10). They developed a 3D architecture using a nanoporous glass plate to entrap [NiFe]-hydrogenase, along a ruthenium photosensitizer, methyl viologen, and an oxygen scavenger, in a reducing environment. They found that the nanopores resisted the influx of $\mathrm{O}_{2}$, and the $\mathrm{MV}^{\bullet+}$ reduced oxygen that penetrated from the external medium. Under aerobic external conditions and visible light illumination, they achieved consistent hydrogen evolution at a rate of $3.7 \mu \mathrm{mol} \mathrm{H}_{2}$ 
$\mathrm{m}^{-2} \mathrm{~s}^{-1}[125]$. Employing the same strategy, they demonstrated that such nanoporous structures can also effect the reduction of $\mathrm{CO}_{2}$ to formic acid by the incorporation of formate dehydrogenase [126]. This strategy can in principle could be extended to semiconductor-based photocatalytic systems, and even drive electrochemical processes if conductive substrates are employed.

\subsection{D-printed advanced structures}

(a)

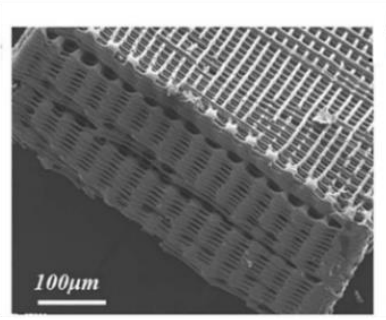

(b)

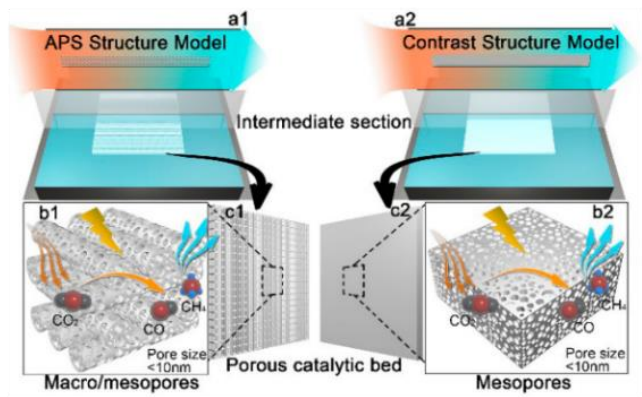

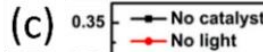

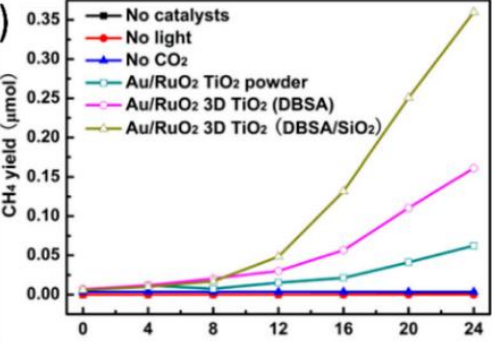

(d)

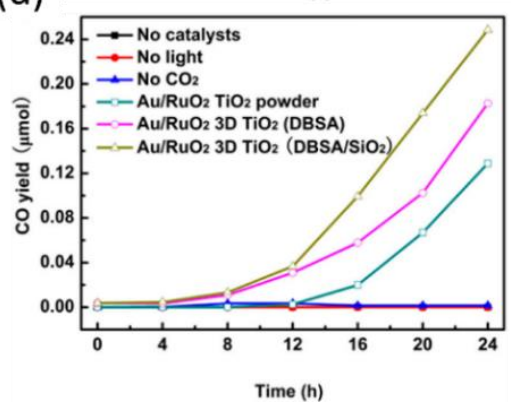

Figure 11 (a) Left - SEM image of the 3D-printed hierarchical structure based on dodecyl benzenesulfonic acid (DBSA) - $\mathrm{TiO}_{2}$ ink and, right - an optical image of a 3D printed artificial leaf. (b) Comparison of gas diffusion between artificial photosynthetic system (APS) and contrast structure model. In both models, mesopores are distributed in the structures but the APS model also features a microporous structure. (c) The production of methane and (d) CO under a range of test conditions.[128] (Reproduced with permission from American Chemical Society). 
3D printing, also known as an additive manufacturing, has been increasingly employed as an attractive approach to fabricate objects via spatially controlled deposition of successive layers of material $[129,130]$. Until recently, 3D printing has been largely limited to the production of relatively bulky items, such as in the aerospace engineering and medical orthopedics fields, but it is now finding increased application toward the fabrication of smaller devices such as micro-supercapacitors [131], microfluidic chips/cells [132], and sensors [133]. Chen et. al recently demonstrated the construction of 3D microleaves via a direct 3D writing method as described below (Figure 11) [128]. Using $\mathrm{TiO}_{2}$-based inks with suitable rheological properties, they incorporated surfactants and silica nanospheres for porosity control. The ink has a high modulus values and flows readily, and quick solidification allows for the construction of a complex hierarchical structural. The approach allowed them to fabricate artificial microleaves with macropore architectures having tunable porosity, exhibiting welldesigned hierarchical 3D architectures and surface areas of up to $\sim 259 \mathrm{~m}^{2} \mathrm{~g}^{-1}$. Theoretical modeling suggests that the macro/mesopores design will allows for superior efficient mass transport diffusion behavior compared to structures that lack the macroporous features but are otherwise similar. This has been confirmed by experiments on $\mathrm{CO}_{2}$ photoreduction: $\mathrm{CO}$ and $\mathrm{CH}_{4}$ evolution on the 3D printed artificial photosynthetic systems (APS) were shown to be enhanced by up to 2- and 6-fold, respectively, relative to rates for corresponding powdered catalytic materials. The authors suggested this approach can be extended to print other 3Dpatterned ceramics. This large-scale printable structure may also offer a platform to incorporate multiple functional components for fully integrated systems for wide-ranging applications.

One approach to enhancing the photocatalytic performance of semiconducting materials is via the surface patterning of metal substrates with advantageous textures and architectures. Several approaches to this end have been reported, albeit each have limitations. Focused ion beam (FIB) lithography, for example, can be used to directly create highly precise patterns in 
the range of tens of nanometers; this slow and sequential technique, however, is difficult to scale up to large substrates. Likewise, nanoimprinting can also be employed to generate nanopatterns but is limited by the Young's modulus of the metal. In one example, Lee et. al. demonstrated the applicability of this approach in the fabrication of metal-based 3D printed photoelectrodes (Figure 12) [134]. Beginning with 3D printed arrays of conical metallic titanium structures which provides a platform for anodic growth of $1 \mathrm{D} \mathrm{TiO}_{2}$ nanotubes, and then annealed them to improve the crystallinity of the semiconducting layer (Figures $12 \mathrm{~b}-\mathrm{f}$ ). A simple electrochemical hydrogenation step further improved the conductivity and photoresponse of the electrodes. The combination of 3D micro- and 1D nanotubular structures provided enhanced surface area and light absorption and proved more effective for photoelectrochemical water splitting. In general, 3D metal printing has the potential to provide a flexible and versatile approach for the design and fabrication of novel electrode structures.
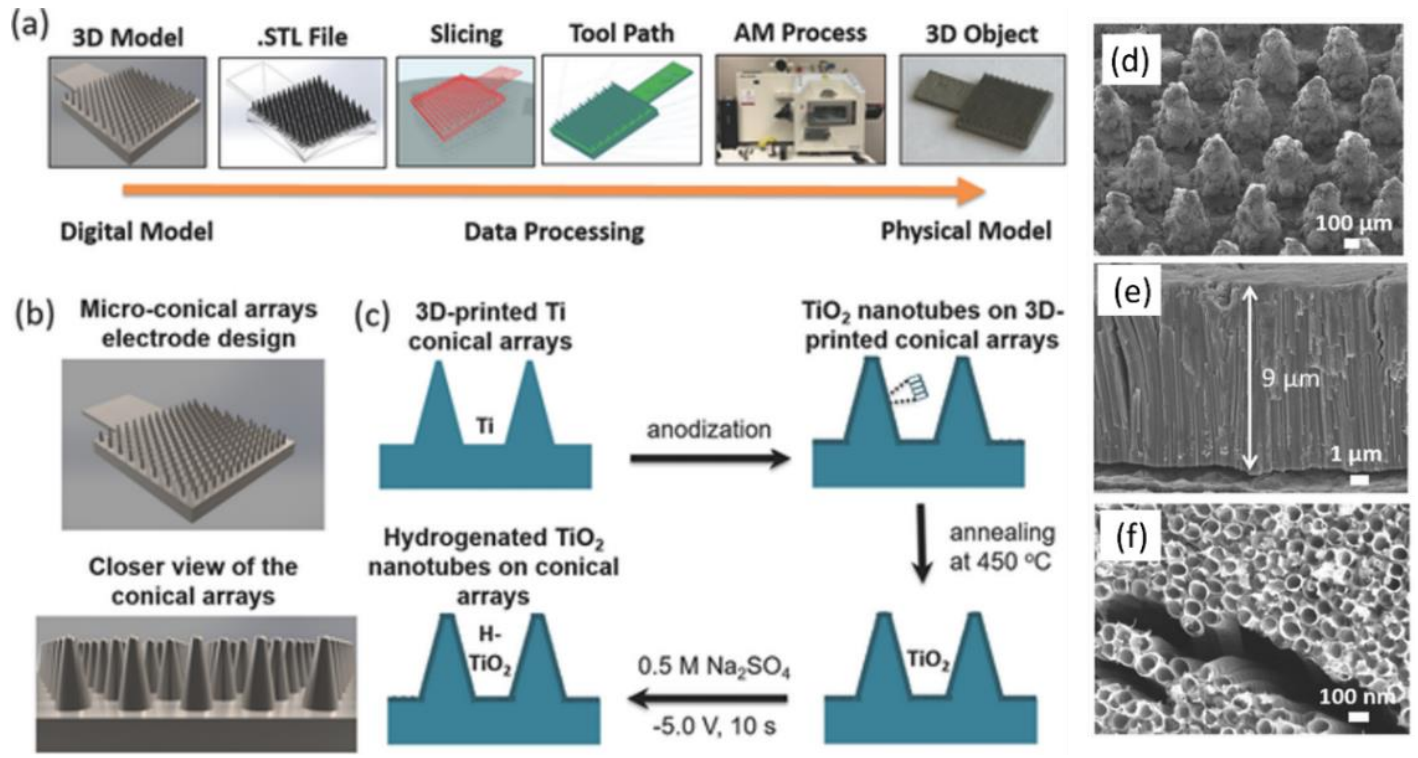

Figure 12 a) Steps in the fabrication of 3D printed electrodes, from software modeling to the physical printing of structures by using Selective Laser Melting machine. b) Ilustrations of the conical-array microstructures. c) Strategy for enhanced functionality by the adornment of 
hydrogenated $1 \mathrm{D}$ nanotubular structures of $\mathrm{TiO}_{2}$ onto the 3D printed microconical arrays. d-f) SEM images of the conical arrays with anodized structures [134] (Reproduced with permission from John Wiley and Son).
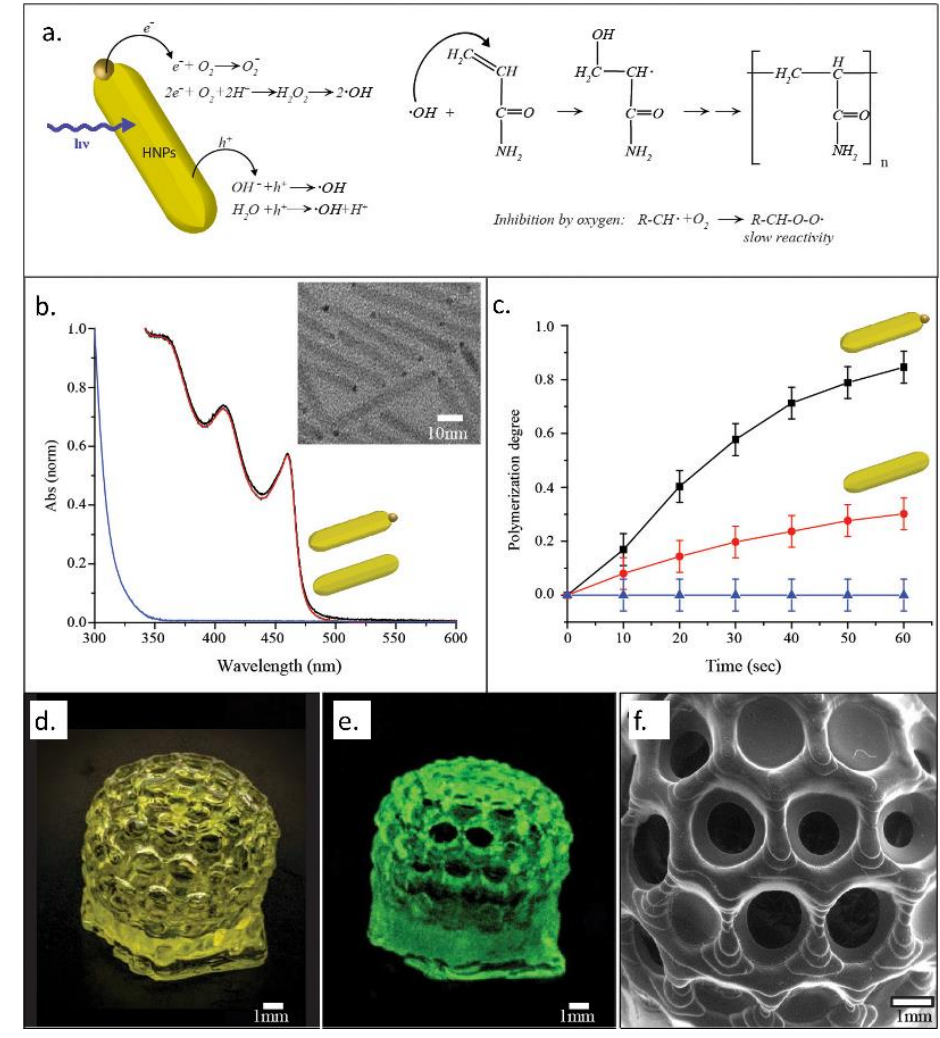

Figure 13 (a) The mechanism of polymerization using hybrid nanoparticles as photoinitiators. Upon light illumination, the photogenerated holes react with the water and hydroxide to form hydroxyl radicals, while the electrons consume the oxygen to form superoxide and hydroxyl radicals. The formed hydroxyl radicals then participate in radical polymerization reaction of acrylamide. (b) Absorption spectra of CdS-Au HNPs (black), bare CdS rods (red) and I2959 (blue). (c) Polymerization degree under UV light at $385 \mathrm{~nm}$ with intensity of $20 \mathrm{~mW} / \mathrm{cm}^{2}$ using CdS-Au (black), CdS (red), and I2959 (blue) as photoinitiators. (d-f) Images of a 3D printed Buckyball using $\mathrm{CdS}-\mathrm{Au}$ HNPs as the photoinitiators and $\mathrm{CdSe} / \mathrm{CdS}$ seeded nanorods as fluorescent markers. Microscopic images of the dried structure using (d) visible light 
illumination, (e) fluorescence imaging under $365 \mathrm{~nm}$ excitation, and (f) SEM. (Reproduced with permission from American Chemical Society).

Interestingly, hybrid semiconductor-metal nanoparticles have been employed as photoinitiators for 3D printing (Figure 13) [135]. Typical photoinitiators are consumed upon irradiation, wherein particular bonds are cleaved to form radical species that begin a chain process. In this hybrid approach, illumination of semiconductor nanorods results in charge separation followed by electron transfer to metal tip which, in turn, reduce water and oxygen to form a variety of reactive radical species. This approach allows $3 \mathrm{D}$ printing in aqueous systems, where the formation of hydroxyl radicals efficiently induce photopolymerization reactions. During this process, dissolved oxygen, which usually retards such polymerizations, is simultaneously consumed. The potential versatility offered by the range of semiconductor and metal composition, as well as the size and shape of the hybrid assemblies, suggest that further optimization of photopolymerizations that utilize 3D printed structures is possible. Moreover, the combination of photocatalytic hybrid semiconductor-metal materials and suitable light harvesting polymers may offer an interesting route toward fabricating 3D photocatalytic systems for solar fuel generations.

\subsection{D-structures assembled from $2 D$ nanosheets}

The discovery of graphene nanosheets [136] has stimulated enormous interest in the potential applications of 2D nanocrystals [29, 137], including their use as photocatalysts. 2Dmaterials possess high specific surface areas and can thereby enhance the availability of active sites and light harvesting capabilities [138]. The short migration distance of photogenerated charge carriers in such structures, along with their high crystallinity, reduces the rate of charge 
recombination [29]. Moreover, the large fraction of exposed surface atoms facilitates the tuning of their defect densities and photocatalytic activity $[139,140]$. There have been several recent attempts to assemble 3D-structures from 2D nanosheets to realize synergic advantages of $2 \mathrm{D}$ and 3D structures. The ultimate goal is the fabrication of 3D-structures with enhanced specific surface areas, mechanical strengths and mass transport properties relative to the individual 2D nanosheets from which they are composed [141-145].

3D structures comprised of 2D nanosheets can fabricated either through self-assembly or 3D template approaches. In self-assembly processes, nanosheets are initially grown in precursor solutions and then allowed to orient themselves, thereby forming the desired 3D structures. Jia et al. synthesized $2 \mathrm{D} \mathrm{Bi}_{2} \mathrm{~S}_{3}$ nanoplatelets via a hydrothermal process and subsequently produced $3 \mathrm{D}$ hierarchical $\mathrm{Bi}_{2} \mathrm{~S}_{3}$ architectures from the Ostwald ripening process (Fig. 14a) [146]. Zhu et al. synthesized 3D BiOCl flowers in which the component 2D nanosheets were interwoven. Tunable microstructures and band energies were achieved by adjusting the ratio of urea and $\mathrm{Bi}^{3+}[147]$.

(a)
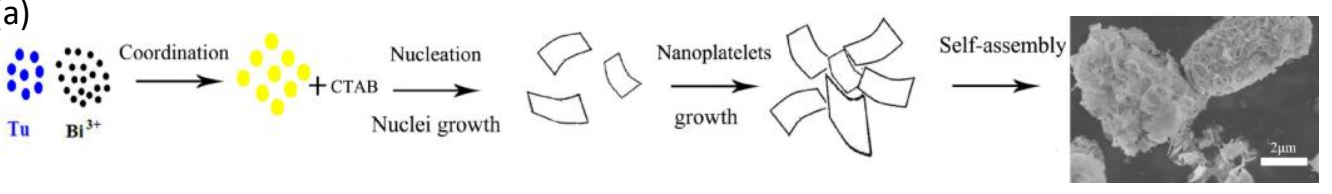

(b)
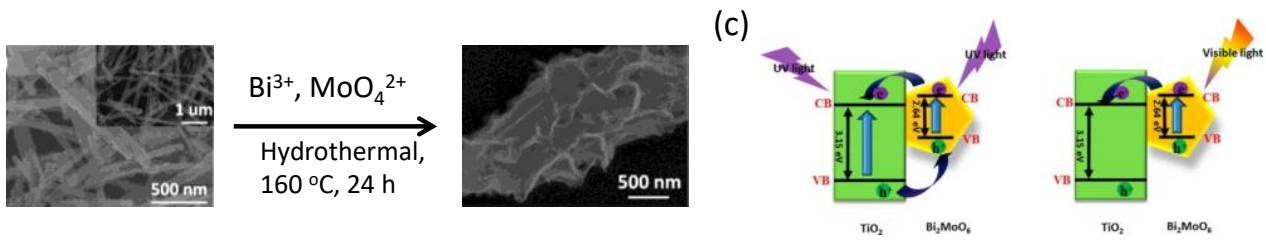

(d)

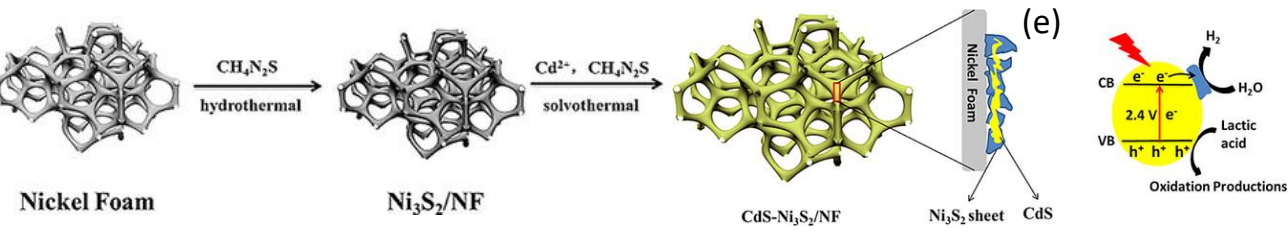


Figure 14 (a) The self-assembly of 2D nanosheet-based 3D hierarchical $\mathrm{Bi}_{2} \mathrm{~S}_{3}$ architectures [146] (Reproduced with permission from MDPI). (b) SEM images of 3D $\mathrm{Bi}_{2} \mathrm{MoO}_{6}$ nanosheet $/ \mathrm{TiO}_{2}$ structures and (c) the corresponding mechanisms of the electron-hole separation [148] (Reproduced with permission from American Chemical Society). (d) Illustration of the $3 \mathrm{D} \mathrm{CdS}-\mathrm{Ni}_{3} \mathrm{~S}_{2} / \mathrm{NF}$ heterostructures and (e) the photocatalytic mechanism of hydrogen production [142] (Reproduced with permission from John Wiley and Son).

A number of 3D assemblies prepared via templates have been successfully prepared for photoelectrochemical water splitting. Templates for 3D assemblies can be foams [149, 150], metal-organic frameworks [151], fibers [152] or belts [148]. In one such approach, Tian et. al. used $\mathrm{TiO}_{2}$ nanobelts decorated with $2 \mathrm{D} \mathrm{Bi}_{2} \mathrm{MoO}_{6}$ nanosheets to build 3D structures [148]. The cross-linked 3D structure effectively utilizes a broad-spectrum of solar light and shows excellent $\mathrm{O}_{2}$ production with different electron-hole separation mechanisms under $\mathrm{UV}$ and visible light illuminations (Figs. $14 \mathrm{~b}$ and $14 \mathrm{c}$ ). Chao et. al. integrated $\mathrm{CdS}$ and $\mathrm{Ni}_{3} \mathrm{~S}_{2}$ nanosheets on nickel foam to construct a 3D structure with abundant junctions and interfaces (Figs. 14d and 14e) [142]. The Ni foam serves as the carrier collector, promoting the separation of photogenerated electrons and holes and enhancing hydrogen evolution. Hong et al. immobilized 2D g- $\mathrm{C}_{3} \mathrm{~N}_{4}$ nanosheets on 3D metal-organic framework [151]. The resulting heterojunctions of nanocomposites exhibited excellent electron-hole separation and improved photocatalysis. Thus the preparation of 3D structures from $2 \mathrm{D}$ nanosheets promises to continue offering new avenues by which the advantages of 2D and 3D structures may be synergistically combined. Specifically, the fabrication of 3D structures with tunable optoelectronic and mechanical properties from 2D nanosheets should afford new photocatalysts with higher performance. 


\section{Conclusion and Outlook}

This review presents a summary of recent work into the effect of photocatalyst dimensionality on the generation of solar fuels. The initial focus was on a hybrid-bioinorganic enzyme system based on OD to 3D photocatalysts, followed by a discussion of a broad range of 3D architectures. The engineering of nanostructured materials and synthetic dyes/ligands has led to substantial reinvestigation of the earliest example of hybrid systems, specifically those combining $\mathrm{TiO}_{2}$ and $\mathrm{CdS}$ OD semiconductors with hydrogenases. Nanorods, 1D semiconductors structures, were found to have superior performance relative to their nanoparticle counterparts. 2D structures are not as widely investigated, but there are several examples of graphene materials integrated with a variety of enzymes. In addition, 2D inorganic photocatalytic systems, especially ultrathin nanosheets, demonstrate beneficial features and can enhance photocatalytic performance. The employment of such structures in hybrid bioinorganic systems may overcome the inefficient charge transfer of photogenerated electron charge carriers from semiconductor surfaces to the active sites of enzymes. Future advances in enzyme immobilisation strategies that provide favourable orientations to facilitate efficient interfacial electron transfer will be especially useful.

The employment of 3D architectures is essential when photocatalysts are to be immobilised on a conductive support, particularly for device-based applications. Some excellent examples of hybrid bioinorganic semi-artificial systems are the structures fashioned from metal oxides, such as ITO and $\mathrm{TiO}_{2}$, that afford well-controlled hierarchical macro/mesoporous architectures. These not only allow high loading of electrocatalysts, but also efficient reactant and product mass transfer. The transparent nature of ITO also allows for the direct loading and incorporation of light-driven enzymes such as PSII at photoelectrodes, or as a support for hydrogenase immobilization on a p-Si photocathode. 
3D structures also make possible the maintenance of conditions conducive to enzyme function and stability, such as the reducing environment established by nanoporous glass plate that allows hydrogenase and $\mathrm{CODH}$ to operate reasonably well under aerobic conditions. Likewise, silicon nanowire arrays not only enhance loading of bacteria, but also facilitates creation of localized anaerobic environment enabling strictly aerobic bacteria to reduce carbon dioxide. 3D printing offers techniques to fabricate and pattern macroporous/mesoporous, and metallic-based conical arrays structures. For the latter, further enhancement in the printing resolution could advance the design of tailor-made electrodes. The application of hybrid semiconductor photocatalysts for the generation of hydroxyl radicals to initiate radical polymerizations was also described; this approach represents a promising prospect for the fabrication of 3D structures that encompass light harvesting polymers and co-catalysts that could be used for solar fuel generation. Finally, the beneficial features of both $2 \mathrm{D}$ and $3 \mathrm{D}$ structures can be combined via the assembly of 3D photocatalysts from $2 \mathrm{D}$ nanosheets.

Of course, the need to translate the promise of 3D structures developed in the lab to largescale practical operation remains a critical issue. For example, the viability of hybrid bioinorganic systems is a concern, as isolated enzymes are very efficient but short-lived under catalytic conditions. Attempts to use whole cells containing hydrogenases, CODH or PSII, as opposed to isolated enzymes, could improve long term stability but at the expense of low efficiency due to the sluggish electron transfer between active sites of enzymes and the electrodes. Nevertheless, some whole cell bacteria/microorganisms are capable of rapid electron transfer to or from electrodes and hold promise for highly efficient photocatalysis as well as long-term durability. In fact, the 3D microarchitectures nature of whole cells providing greater flexibility in hybrid photocatalytic systems. The deposition of nanoscale lightharvesting inorganic materials allows for self-photosensitization and self-replication of nonphotosynthetic bacteria with greater efficacy and stability for solar fuel generation. Looking 
forward, advances in bioengineering, that is the design of more robust enzymes via mutation or other genetic manipulation, could improve the stability of hybrid systems, and whole cells in combination with specific design 3D architectures may also improve the durability of hybrid bioinorganic systems. 3D printing strategies for the inorganic photocatalytic systems described in section 4.2 may also be employed to design tailored-made structures that afford enhanced enzyme loading, as well as anaerobic protective architecture that may be useful in bioinorganic systems. Likewise, assemblies of 2D nanosheets to form 3D structures can be used to load large quantity of enzymes in hybrid systems.

The semiconductor-bioinorganic systems reported thus far generally exhibit relatively low quantum efficiency $(<6 \%)$ compared to inorganic photocatalytic systems, which can exceed $10 \%$, reflecting the underlying truism that biological systems are selected for biological fitness rather than high efficiency. Advances in multidisciplinary approaches involving synthetic biology and materials science are still necessary to realize the rational design of optimal semiconductor-enzyme interfaces. Hence for both hybrid bioinorganic or purely inorganic systems, solar fuel generation via semiconductor photocatalysts remains elusive and will require the enhancement of overall efficiencies of three key components: light absorption, charge-separation, and catalysis. As 3D architecture consists of connecting networks that may further complicate the directionality of photogenerated electrons and holes, efficient interfacial charge-transfer when coupling with co-catalysts becomes a critical aspect of overall performance. Therefore, there remains intense focus on finding and fabricating photocatalysts with $3 \mathrm{D}$ architectures that will facilitate the optimisation and integration of these components.

Acknowledgments: Fundings from the University of Wollongong for Vice Chancellor's Research Fellowship (to. C.Y. L.) and the Australian Research Council Centre of Excellence 
Scheme (CE 140100012) is gratefully acknowledged. We thank Australian National Fabrication Facility-Materials Node (ANFF) for facility access.

Conflicts of Interest: The authors declare no conflict of interest. 


\section{References}

[1] A. Fujishima, K. Honda, Electrochemical photolysis of water at a semiconductor electrode, Nature, 238 (1972) 37.

[2] A.J. Bard, Photoelectrochemistry, Science, 207 (1980) 139-144.

[3] D. Duonghond, N. Serpone, M. Grätzel, Integrated systems for water cleavage by visible light; sensitization of $\mathrm{TiO}_{2}$ particles by surface derivatization with ruthenium complexes, Helv. Chim. Acta, 67 (1984) 1012-1018.

[4] N. Serpone, E. Pelizzetti, M. Gratzel, Photosensitization of semiconductors with transition metal complexes - a route to the photoassisted cleavage of water, Coord. Chem. Rev., 64 (1985) $225-245$.

[5] A. Ueno, N. Kakuta, K.H. Park, M.F. Finlayson, A.J. Bard, A. Campion, M.A. Fox, S.E. Webber, J.M. White, Silica-supported ZnS.cntdot.CdS mixed semiconductor catalysts for photogeneration of hydrogen, J. Phys. Chem., 89 (1985) 3828-3833.

[6] S. Banerjee, D.D. Dionysiou, S.C. Pillai, Self-cleaning applications of $\mathrm{TiO}_{2}$ by photoinduced hydrophilicity and photocatalysis, Appl. Catal. B: Environ., 176-177 (2015) 396-428. [7] L. Caballero, K.A. Whitehead, N.S. Allen, J. Verran, Inactivation of Escherichia coli on immobilized $\mathrm{TiO}_{2}$ using fluorescent light, J. Photochem. Photobiol. A, 202 (2009) 92-98.

[8] X. Chen, S.S. Mao, Titanium dioxide nanomaterials: synthesis, properties, modifications, and applications, Chem. Rev., 107 (2007) 2891-2959.

[9] V. Etacheri, C. Di Valentin, J. Schneider, D. Bahnemann, S.C. Pillai, Visible-light activation of $\mathrm{TiO}_{2}$ photocatalysts: advances in theory and experiments, J. Photochem. Photobiol. C, 25 (2015) 1-29.

[10] R. Fagan, D.E. McCormack, D.D. Dionysiou, S.C. Pillai, A review of solar and visible light active $\mathrm{TiO}_{2}$ photocatalysis for treating bacteria, cyanotoxins and contaminants of emerging concern, Mat. Sci. Semicon. Proc., 42 (2016) 2-14.

[11] A. Fujishima, T.N. Rao, D.A. Tryk, Titanium dioxide photocatalysis, J. Photochem. Photobiol. C, 1 (2000) 1-21. 
[12] A. Fujishima, X. Zhang, D.A. Tryk, Heterogeneous photocatalysis: from water photolysis to applications in environmental cleanup, Int. J. Hydrog. Energy, 32 (2007) 2664-2672.

[13] M.R. Hoffmann, S.T. Martin, W. Choi, D.W. Bahnemann, Environmental applications of semiconductor photocatalysis, Chem. Rev., 95 (1995) 69-96.

[14] T. Inoue, A. Fujishima, S. Konishi, K. Honda, Photoelectrocatalytic reduction of carbon dioxide in aqueous suspensions of semiconductor powders, Nature, 277 (1979) 637.

[15] H. Kazuhito, I. Hiroshi, F. Akira, $\mathrm{TiO}_{2}$ photocatalysis: a historical overview and future prospects, Jpn. J. Appl. Phys., 44 (2005) 8269.

[16] T. Matsunaga, R. Tomoda, T. Nakajima, H. Wake, Photoelectrochemical sterilization of microbial cells by semiconductor powders, FEMS Microbiol. Lett., 29 (1985) 211-214.

[17] K. Nakata, A. Fujishima, $\mathrm{TiO}_{2}$ photocatalysis: design and applications, J. Photochem. Photobiol. C, 13 (2012) 169-189.

[18] P. Roy, S. Berger, P. Schmuki, $\mathrm{TiO}_{2}$ Nanotubes: synthesis and applications, Angew. Chem. Int. Ed., 50 (2011) 2904-2939.

[19] E. Holden, K. Linnerud, D. Banister, Sustainable development: our common future revisited, Global Environ. Chang., 26 (2014) 130-139.

[20] P.M. Hannam, Z. Liao, S.J. Davis, M. Oppenheimer, Developing country finance in a post-2020 global climate agreement, Mat. Climate Change, 5 (2015) 983.

[21] X. Chen, S. Shen, L. Guo, S.S. Mao, Semiconductor-based photocatalytic hydrogen generation, Chem. Rev., 110 (2010) 6503-6570.

[22] T. Hisatomi, J. Kubota, K. Domen, Recent advances in semiconductors for photocatalytic and photoelectrochemical water splitting, Chem. Soc. Rev., 43 (2014) 7520-7535.

[23] F.E. Osterloh, Inorganic materials as catalysts for photochemical splitting of water, Chem. Mater., 20 (2008) 35-54.

[24] F.E. Osterloh, Inorganic nanostructures for photoelectrochemical and photocatalytic water splitting, Chem. Soc. Rev., 42 (2013) 2294-2320.

[25] M. Pelaez, N.T. Nolan, S.C. Pillai, M.K. Seery, P. Falaras, A.G. Kontos, P.S.M. Dunlop, J.W.J. Hamilton, J.A. Byrne, K. O'Shea, M.H. Entezari, D.D. Dionysiou, A review on the 
visible light active titanium dioxide photocatalysts for environmental applications, Appl. Catal. B: Environ., 125 (2012) 331-349.

[26] C. Tan, X. Cao, X.-J. Wu, Q. He, J. Yang, X. Zhang, J. Chen, W. Zhao, S. Han, G.-H. Nam, M. Sindoro, H. Zhang, Recent advances in ultrathin two-dimensional nanomaterials, Chem. Rev., 117 (2017) 6225-6331.

[27] J. Twilton, C. Le, P. Zhang, M.H. Shaw, R.W. Evans, D.W.C. MacMillan, The merger of transition metal and photocatalysis, Nat. Rev., 1 (2017) 0052.

[28] H. Wang, L. Zhang, Z. Chen, J. Hu, S. Li, Z. Wang, J. Liu, X. Wang, Semiconductor heterojunction photocatalysts: design, construction, and photocatalytic performances, Chem. Soc. Rev., 43 (2014) 5234-5244.

[29] H. Wang, X. Zhang, Y. Xie, Recent progress in ultrathin two-dimensional semiconductors for photocatalysis, Mater. Sci. Eng. R., 130 (2018) 1-39.

[30] X. Li, J. Yu, M. Jaroniec, Hierarchical photocatalysts, Chem. Soc. Rev., 45 (2016) $2603-$ 2636.

[31] X.-Y. Yang, L.-H. Chen, Y. Li, J.C. Rooke, C. Sanchez, B.-L. Su, Hierarchically porous materials: synthesis strategies and structure design, Chem. Soc. Rev., 46 (2017) 481-558.

[32] J. Low, S. Cao, J. Yu, S. Wageh, Two-dimensional layered composite photocatalysts, Chem. Commun., 50 (2014) 10768-10777.

[33] M.J. Wu, J.Z. Wu, J. Zhang, H. Chen, J.Z. Zhou, G.R. Qian, Z.P. Xu, Z. Du, Q.L. Rao, A review on fabricating heterostructures from layered double hydroxides for enhanced photocatalytic activities, Catal. Sci. Technol., 8 (2018) 1207-1228.

[34] Y. Zhao, G.I.N. Waterhouse, G. Chen, X. Xiong, L.-Z. Wu, C.-H. Tung, T. Zhang, Twodimensional-related catalytic materials for solar-driven conversion of $\mathrm{CO}_{\mathrm{x}}$ into valuable chemical feedstocks, Chem. Soc. Rev., (2019).

[35] R. Shi, Y. Cao, Y. Bao, Y. Zhao, G.I.N. Waterhouse, Z. Fang, L.-Z. Wu, C.-H. Tung, Y. Yin, T. Zhang, Self-assembled Au/CdSe nanocrystal clusters for plasmon-mediated photocatalytic hydrogen evolution, Adv. Mater., 29 (2017) 1700803. 
[36] M. Watanabe, Y. Honda, H. Hagiwara, T. Ishihara, [FeFe]-hydrogenase and its organic molecule mimics-artificial and bioengineering application for hydrogenproduction, J. Photochem. Photobiol. C, 33 (2017) 1-26.

[37] S.H. Lee, D.S. Choi, S.K. Kuk, C.B. Park, Photobiocatalysis: activating redox enzymes by direct or indirect transfer of photoinduced electrons, Angew. Chem. Int. Ed., 57 (2018) 7958-7985.

[38] N. Kornienko, J.Z. Zhang, K.K. Sakimoto, P. Yang, E. Reisner, Interfacing nature's catalytic machinery with synthetic materials for semi-artificial photosynthesis, Nat. Nanotech., 13 (2018) 890-899.

[39] C.M. Lieber, One-dimensional nanostructures: chemistry, physics \& applications, Solid. State Comm., 107 (1998) 607-616.

[40] C. Weisbuch, B. Vinter, CHAPTER VI - Towards 1D and 0D physics and devices, in: C. Weisbuch, B. Vinter (Eds.) Quantum semiconductor structures, Academic Press, San Diego, (1991) pp. 189-215.

[41] J.A. Cracknell, K.A. Vincent, F.A. Armstrong, Enzymes as working or inspirational electrocatalysts for fuel cells and electrolysis, Chem. Rev., 108 (2008) 2439-2461.

[42] K.A. Vincent, A. Parkin, F.A. Armstrong, Investigating and exploiting the electrocatalytic properties of hydrogenases, Chem. Rev., 107 (2007) 4366-4413.

[43] A.K. Jones, E. Sillery, S.P.J. Albracht, F.A. Armstrong, Direct comparison of the electrocatalytic oxidation of hydrogen by an enzyme and a platinum catalyst, Chem. Commun., (2002) 866-867.

[44] K. Nath, M.M. Najafpour, R.A. Voloshin, S.E. Balaghi, E. Tyystjärvi, R. Timilsina, J.J. Eaton-Rye, T. Tomo, H.G. Nam, H. Nishihara, S. Ramakrishna, J.-R. Shen, S.I. Allakhverdiev, Photobiological hydrogen production and artificial photosynthesis for clean energy: from bio to nanotechnologies, Photosynth. Res., 126 (2015) 237-247.

[45] S. Meher Kotay, D. Das, Biohydrogen as a renewable energy resource-Prospects and potentials, Int. J. Hydrog. Energy, 33 (2008) 258-263.

[46] W. Lubitz, H. Ogata, O. Rüdiger, E. Reijerse, Hydrogenases, Chem. Rev., 114 (2014) 4081-4148. 
[47] A. Parkin, G. Goldet, C. Cavazza, J.C. Fontecilla-Camps, F.A. Armstrong, The difference a Se makes? Oxygen-tolerant hydrogen production by the [NiFeSe]-hydrogenase from Desulfomicrobium baculatum, J. Am. Chem. Soc., 130 (2008) 13410-13416.

[48] Y. Honda, H. Hagiwara, S. Ida, T. Ishihara, Application to photocatalytic $\mathrm{H}_{2}$ production of a whole-cell reaction by recombinant Escherichia coli cells expressing [FeFe]-hydrogenase and maturases genes, Angew. Chem. Int. Ed., 55 (2016) 8045-8048.

[49] B. Wang, C. Zeng, K.H. Chu, D. Wu, H.Y. Yip, L. Ye, P.K. Wong, Enhanced biological hydrogen production from Escherichia coli with surface precipitated cadmium sulfide nanoparticles, Adv. Energy Mater., 7 (2017) 1700611.

[50] P. Cuendet, M. Grätzel, M.L. Pélaprat, Viologen-derivatization of $\mathrm{TiO}_{2}$ particles and lightinduced $\mathrm{H}_{2}$ evolution by immobilized hydrogenase, J. Electroanal. Chem., 181 (1984) 173-185. [51] P. Cuendet, K.K. Rao, M. Grätzel, D.O. Hall, Light induced $\mathrm{H}_{2}$ evolution in a hydrogenase- $\mathrm{TiO}_{2}$ particle system by direct electron transfer or via rhodium complexes, Biochimie, 68 (1986) 217-221.

[52] A. Selvaggi, C. Tosi, U. Barberini, E. Franchi, F. Rodriguez, P. Pedroni, In vitro hydrogen photoproduction using Pyrococcus furiosus sulfhydrogenase and $\mathrm{TiO}_{2}$, J. Photochem. Photobiol. A, 125 (1999) 107-112.

[53] P. Pedroni, G.M. Mura, G. Galli, C. Pratesi, L. Serbolisca, G. Grandi, The hydrogenase from the hyperthermophilic archaeon Pyrococcus furiosus: from basic research to possible future applications, Int. J. Hydrog. Energy, 21 (1996) 853-858.

[54] I.A. Shumilin, V.V. Nikandrov, V.O. Popov, A.A. Krasnovsky, Photogeneration of $\mathrm{NADH}$ under coupled action of $\mathrm{CdS}$ semiconductor and hydrogenase from Alcaligenes eutrophus without exogenous mediators, FEBS Lett., 306 (1992) 125-128.

[55] V.V. Nikandrov, M.A. Shlyk, N.A. Zorin, I.N. Gogotov, A.A. Krasnovsky, Efficient photoinduced electron transfer from inorganic semiconductor $\mathrm{TiO}_{2}$ to bacterial hydrogenase, FEBS Lett., 234 (1988) 111-114.

[56] E. Reisner, J.C. Fontecilla-Camps, F.A. Armstrong, Catalytic electrochemistry of a [NiFeSe]-hydrogenase on $\mathrm{TiO}_{2}$ and demonstration of its suitability for visible-light driven $\mathrm{H}_{2}$ production, Chem. Commun., (2009) 550-552. 
[57] E. Reisner, D.J. Powell, C. Cavazza, J.C. Fontecilla-Camps, F.A. Armstrong, Visible lightdriven $\mathrm{H}_{2}$ production by hydrogenases attached to dye-sensitized $\mathrm{TiO}_{2}$ nanoparticles, J. Am. Chem. Soc., 131 (2009) 18457-18466.

[58] S.V. Hexter, F. Grey, T. Happe, V. Climent, F.A. Armstrong, Electrocatalytic mechanism of reversible hydrogen cycling by enzymes and distinctions between the major classes of hydrogenases, Proc. Natl. Acad. Sci. USA, 109 (2012) 11516-11521.

[59] K.A. Brown, S. Dayal, X. Ai, G. Rumbles, P.W. King, Controlled assembly of hydrogenase-CdTe nanocrystal hybrids for solar hydrogen production, J. Am. Chem. Soc., 132 (2010) 9672-9680.

[60] K.A. Brown, M.B. Wilker, M. Boehm, G. Dukovic, P.W. King, Characterization of photochemical processes for $\mathrm{H}_{2}$ production by $\mathrm{CdS}$ nanorod-[FeFe] hydrogenase complexes, J. Am. Chem. Soc., 134 (2012) 5627-5636.

[61] M.B. Wilker, K.E. Shinopoulos, K.A. Brown, D.W. Mulder, P.W. King, G. Dukovic, Electron transfer kinetics in $\mathrm{CdS}$ nanorod-[FeFe]-hydrogenase complexes and implications for photochemical $\mathrm{H}_{2}$ generation, J. Am. Chem. Soc., 136 (2014) 4316-4324.

[62] M.B. Wilker, J.K. Utterback, S. Greene, K.A. Brown, D.W. Mulder, P.W. King, G. Dukovic, Role of surface-capping ligands in photoexcited electron transfer between $\mathrm{CdS}$ nanorods and $[\mathrm{FeFe}]$ hydrogenase and the subsequent $\mathrm{H}_{2}$ generation, J. Phys. Chem. $\mathrm{C}, 122$ (2018) 741-750.

[63] A.A. Krasnovsky, V.V. Nikandrov, The photobiocatalytic system: inorganic semiconductors coupled to bacterial cells, FEBS Lett., 219 (1987) 93-96.

[64] P. Maruthamuthu, S. Muthu, K. Gurunathan, M. Ashokkumar, M.V.C. Sastri, Photobiocatalysis: hydrogen evolution using a semiconductor coupled with photosynthetic bacteria, Int. J. Hydrog. Energy, 17 (1992) 863-866.

[65] K. Gurunathan, Photobiocatalytic production of hydrogen using sensitized $\mathrm{TiO}_{2}-\mathrm{MV}^{2+}$ system coupled Rhodopseudomonas capsulata, J. Molec. Catal. A-Chem., 156 (2000) 59-67.

[66] Y. Honda, M. Watanabe, H. Hagiwara, S. Ida, T. Ishihara, Inorganic/whole-cell biohybrid photocatalyst for highly efficient hydrogen production from water, Appl. Catal. B: Environ., 210 (2017) 400-406. 
[67] K.K. Sakimoto, A.B. Wong, P. Yang, Self-photosensitization of nonphotosynthetic bacteria for solar-to-chemical production, Science, 351 (2016) 74-77.

[68] Z. Jiang, B. Wang, J.C. Yu, J. Wang, T. An, H. Zhao, H. Li, S. Yuan, P.K. Wong, $A g \ln S_{2} / \operatorname{In}_{2} S_{3}$ heterostructure sensitization of Escherichia coli for sustainable hydrogen production, Nano Energy, 46 (2018) 234-240.

[69] W. Wei, P. Sun, Z. Li, K. Song, W. Su, B. Wang, Y. Liu, J. Zhao, A surface-display biohybrid approach to light-driven hydrogen production in air, Sci. Adv., 4 (2018) 9253.

[70] A. Parkin, J. Seravalli, K.A. Vincent, S.W. Ragsdale, F.A. Armstrong, Rapid and efficient electrocatalytic $\mathrm{CO}_{2} / \mathrm{CO}$ interconversions by Carboxydothermus hydrogenoformans $\mathrm{CO}$ dehydrogenase I on an electrode, J. Am. Chem. Soc., 129 (2007) 10328-10329.

[71] T.W. Woolerton, S. Sheard, E. Reisner, E. Pierce, S.W. Ragsdale, F.A. Armstrong, Efficient and clean photoreduction of $\mathrm{CO}_{2}$ to $\mathrm{CO}$ by enzyme-modified $\mathrm{TiO}_{2}$ nanoparticles using visible light, J. Am. Chem. Soc., 132 (2010) 2132-2133.

[72] Y.S. Chaudhary, T.W. Woolerton, C.S. Allen, J.H. Warner, E. Pierce, S.W. Ragsdale, F.A. Armstrong, Visible light-driven $\mathrm{CO}_{2}$ reduction by enzyme coupled $\mathrm{CdS}$ nanocrystals, Chem. Commun., 48 (2012) 58-60.

[73] M. Can, F.A. Armstrong, S.W. Ragsdale, Structure, function, and mechanism of the nickel metalloenzymes, CO dehydrogenase, and acetyl-CoA synthase, Chem. Rev., 114 (2014) 41494174.

[74] L.B. Maia, L. Fonseca, I. Moura, J.J.G. Moura, Reduction of Carbon Dioxide by a molybdenum-containing formate dehydrogenase: a kinetic and mechanistic study, J. Am. Chem. Soc., 138 (2016) 8834-8846.

[75] T. Reda, C.M. Plugge, N.J. Abram, J. Hirst, Reversible interconversion of carbon dioxide and formate by an electroactive enzyme, Proc. Natl. Acad. Sci. USA, 105 (2008) 10654-10658. [76] A. Bassegoda, C. Madden, D.W. Wakerley, E. Reisner, J. Hirst, Reversible interconversion of $\mathrm{CO}_{2}$ and formate by a molybdenum-containing formate dehydrogenase, $\mathrm{J}$. Am. Chem. Soc., 136 (2014) 15473-15476. 
[77] K. Sakai, Y. Kitazumi, O. Shirai, K. Kano, Bioelectrocatalytic formate oxidation and carbon dioxide reduction at high current density and low overpotential with tungstencontaining formate dehydrogenase and mediators, Electrochem. Commun., 65 (2016) 31-34.

[78] K. Sakai, B.-C. Hsieh, A. Maruyama, Y. Kitazumi, O. Shirai, K. Kano, Interconversion between formate and hydrogen carbonate by tungsten-containing formate dehydrogenasecatalyzed mediated bioelectrocatalysis, Sens. Biosensing Res., 5 (2015) 90-96.

[79] S.Y. Lee, S.Y. Lim, D. Seo, J.-Y. Lee, T.D. Chung, Light-driven highly selective conversion of $\mathrm{CO}_{2}$ to formate by electrosynthesized enzyme/cofactor thin film electrode, $\mathrm{Adv}$. Energy Mater., 6 (2016) 1502207.

[80] D.H. Nam, S.K. Kuk, H. Choe, S. Lee, J.W. Ko, E.J. Son, E.-G. Choi, Y.H. Kim, C.B. Park, Enzymatic photosynthesis of formate from carbon dioxide coupled with highly efficient photoelectrochemical regeneration of nicotinamide cofactors, Green Chem., 18 (2016) 59895993.

[81] H.L. Drake, Acetogenesis, Springer Science \& Business Media, (2012).

[82] J. Daniell, M. Köpke, S.D. Simpson, Commercial biomass syngas fermentation, Energies, 5 (2012) 5372.

[83] B.A. Parkinson, P.F. Weaver, Photoelectrochemical pumping of enzymatic $\mathrm{CO}_{2}$ reduction, Nature, 309 (1984) 148.

[84] T.W. Woolerton, S. Sheard, E. Pierce, S.W. Ragsdale, F.A. Armstrong, $\mathrm{CO}_{2}$ photoreduction at enzyme-modified metal oxide nanoparticles, Energy Environ. Sci., 4 (2011) 2393-2399.

[85] L. Zhang, M. Can, S.W. Ragsdale, F.A. Armstrong, Fast and selective photoreduction of $\mathrm{CO}_{2}$ to $\mathrm{CO}$ catalyzed by a complex of carbon monoxide dehydrogenase, $\mathrm{TiO}_{2}$, and $\mathrm{Ag}$ nanoclusters, ACS Catal., 8 (2018) 2789-2795.

[86] R.K. Yadav, G.H. Oh, N.-J. Park, A. Kumar, K.-j. Kong, J.-O. Baeg, Highly selective solar-driven methanol from $\mathrm{CO}_{2}$ by a photocatalyst/biocatalyst integrated system, J. Am. Chem. Soc., 136 (2014) 16728-16731. 
[87] R.K. Yadav, J.-O. Baeg, G.H. Oh, N.-J. Park, K.-j. Kong, J. Kim, D.W. Hwang, S.K. Biswas, A photocatalyst-enzyme coupled artificial photosynthesis system for solar energy in production of formic acid from $\mathrm{CO}_{2}$, J. Am. Chem. Soc., 134 (2012) 11455-11461.

[88] K.K. Sakimoto, S.J. Zhang, P. Yang, Cysteine-cystine photoregeneration for oxygenic photosynthesis of acetic acid from $\mathrm{CO}_{2}$ by a tandem inorganic-biological hybrid system, Nano Lett., 16 (2016) 5883-5887.

[89] K.P. Nevin, S.A. Hensley, A.E. Franks, Z.M. Summers, J. Ou, T.L. Woodard, O.L. Snoeyenbos-West, D.R. Lovley, Electrosynthesis of organic compounds from carbon dioxide is catalyzed by a diversity of acetogenic microorganisms, Appl. Environ. Microbiol., 77 (2011) 2882-2886.

[90] H. Zhang, H. Liu, Z. Tian, D. Lu, Y. Yu, S. Cestellos-Blanco, K.K. Sakimoto, P. Yang, Bacteria photosensitized by intracellular gold nanoclusters for solar fuel production, Nat. Nanotech., 13 (2018) 900-905.

[91] F.A. Armstrong, N.A. Belsey, J.A. Cracknell, G. Goldet, A. Parkin, E. Reisner, K.A. Vincent, A.F. Wait, Dynamic electrochemical investigations of hydrogen oxidation and production by enzymes and implications for future technology, Chem. Soc. Rev., 38 (2009) 36-51.

[92] N.D.J. Yates, M.A. Fascione, A. Parkin, Methodologies for "wiring" redox proteins/enzymes to electrode surfaces, Chem. Euro. J., 24 (2018) 12164-12182.

[93] V. Hitaishi, R. Clement, N. Bourassin, M. Baaden, A. de Poulpiquet, S. Sacquin-Mora, A. Ciaccafava, E. Lojou, controlling redox enzyme orientation at planar electrodes, Catalysts, 8 (2018) 192.

[94] R.L. McCreery, Advanced carbon electrode materials for molecular electrochemistry, Chem. Rev., 108 (2008) 2646-2687.

[95] C.E. Banks, R.G. Compton, New electrodes for old: from carbon nanotubes to edge plane pyrolytic graphite, Analyst, 131 (2006) 15-21.

[96] M. Hambourger, M. Gervaldo, D. Svedruzic, P.W. King, D. Gust, M. Ghirardi, A.L. Moore, T.A. Moore, $[\mathrm{FeFe}]$-hydrogenase-catalyzed $\mathrm{H}_{2}$ production in a photoelectrochemical biofuel cell, J. Am. Chem. Soc., 130 (2008) 2015-2022. 
[97] T. Kihara, X.-Y. Liu, C. Nakamura, K.-M. Park, S.-W. Han, D.-J. Qian, K. Kawasaki, N.A. Zorin, S. Yasuda, K. Hata, T. Wakayama, J. Miyake, Direct electron transfer to hydrogenase for catalytic hydrogen production using a single-walled carbon nanotube forest, Int. J. Hydrog. Energy, 36 (2011) 7523-7529.

[98] X. Yu, D. Chattopadhyay, I. Galeska, F. Papadimitrakopoulos, J.F. Rusling, Peroxidase activity of enzymes bound to the ends of single-wall carbon nanotube forest electrodes, Electrochem. Commun., 5 (2003) 408-411.

[99] R. Braun, M. Sarikaya, K. Schulten, Genetically engineered gold-binding polypeptides: structure prediction and molecular dynamics, J. Biomater. Sci. Polym. Ed., 13 (2002) 747-757. [100] S. Morra, F. Valetti, S.J. Sadeghi, P.W. King, T. Meyer, G. Gilardi, Direct electrochemistry of an [FeFe]-hydrogenase on a $\mathrm{TiO}_{2}$ electrode, Chem. Commun., 47 (2011) 10566-10568.

[101] S. Morra, F. Valetti, V. Sarasso, S. Castrignanò, S.J. Sadeghi, G. Gilardi, Hydrogen production at high Faradaic efficiency by a bio-electrode based on $\mathrm{TiO}_{2}$ adsorption of a new [FeFe]-hydrogenase from Clostridium perfringens, Bioelectrochem., 106 (2015) 258-262.

[102] E. Topoglidis, C.J. Campbell, A.E.G. Cass, J.R. Durrant, Factors that affect protein adsorption on nanostructured titania films. A novel spectroelectrochemical application to sensing, Langmuir, 17 (2001) 7899-7906.

[103] A. Bachmeier, S. Hall, S.W. Ragsdale, F.A. Armstrong, Selective visible-light-driven $\mathrm{CO}_{2}$ reduction on a p-type dye-sensitized NiO photocathode, J. Am. Chem. Soc., 136 (2014) 13518-13521.

[104] C.-Y. Lee, H.S. Park, J.C. Fontecilla-Camps, E. Reisner, Photoelectrochemical $\mathrm{H}_{2}$ evolution with a hydrogenase immobilized on a $\mathrm{TiO}_{2}$-protected silicon electrode, Angew. Chem. Int. Ed., 55 (2016) 5971-5974.

[105] P. Qin, H. Zhu, T. Edvinsson, G. Boschloo, A. Hagfeldt, L. Sun, Design of an organic chromophore for p-type dye-sensitized solar cells, J. Am. Chem. Soc., 130 (2008) 8570-8571. [106] L. Li, L. Duan, F. Wen, C. Li, M. Wang, A. Hagfeldt, L. Sun, Visible light driven hydrogen production from a photo-active cathode based on a molecular catalyst and organic dye-sensitized p-type nanostructured NiO, Chem. Commun., 48 (2012) 988-990. 
[107] Y. Zhao, N.C. Anderson, M.W. Ratzloff, D.W. Mulder, K. Zhu, J.A. Turner, N.R. Neale, P.W. King, H.M. Branz, Proton reduction using a hydrogenase-modified nanoporous black silicon photoelectrode, ACS Appl. Mater. Inter., 8 (2016) 14481-14487.

[108] D. Mersch, C.-Y. Lee, J.Z. Zhang, K. Brinkert, J.C. Fontecilla-Camps, A.W. Rutherford, E. Reisner, Wiring of photosystem II to hydrogenase for photoelectrochemical water splitting, J. Am. Chem. Soc., 137 (2015) 8541-8549.

[109] D.H. Nam, J.Z. Zhang, V. Andrei, N. Kornienko, N. Heidary, A. Wagner, K. Nakanishi, K.P. Sokol, B. Slater, I. Zebger, S. Hofmann, J.C. Fontecilla-Camps, C.B. Park, E. Reisner, Solar water splitting with a hydrogenase integrated in photoelectrochemical tandem cells, Angew. Chem. Int. Ed., 57 (2018) 10595-10599.

[110] K.P. Sokol, W.E. Robinson, J. Warnan, N. Kornienko, M.M. Nowaczyk, A. Ruff, J.Z. Zhang, E. Reisner, Bias-free photoelectrochemical water splitting with photosystem II on a dye-sensitized photoanode wired to hydrogenase, Nat. Energy, (2018) 944.

[111] M. Kato, T. Cardona, A.W. Rutherford, E. Reisner, Photoelectrochemical water oxidation with photosystem II integrated in a mesoporous indium-tin oxide electrode, J. Am. Chem. Soc., 134 (2012) 8332-8335.

[112] N. Kornienko, J.Z. Zhang, K.P. Sokol, S. Lamaison, A. Fantuzzi, R. van Grondelle, A.W. Rutherford, E. Reisner, Oxygenic photoreactivity in photosystem II studied by rotating ring disk electrochemistry, J. Am. Chem. Soc., 140 (2018)17923-17931.

[113] C.-Y. Lee, B. Reuillard, K.P. Sokol, T. Laftsoglou, C.W.J. Lockwood, S.F. Rowe, E.T. Hwang, J.C. Fontecilla-Camps, L.J.C. Jeuken, J.N. Butt, E. Reisner, A decahaem cytochrome as an electron conduit in protein-enzyme redox processes, Chem. Commun., 52 (2016) 73907393.

[114] D. Ciornii, M. Riedel, K.R. Stieger, S.C. Feifel, M. Hejazi, H. Lokstein, A. Zouni, F. Lisdat, Bioelectronic circuit on a 3D electrode architecture: enzymatic catalysis interconnected with photosystem I, J. Am. Chem. Soc., 139 (2017) 16478-16481.

[115] C. Liu, J.J. Gallagher, K.K. Sakimoto, E.M. Nichols, C.J. Chang, M.C.Y. Chang, P. Yang, Nanowire-bacteria hybrids for unassisted solar carbon dioxide fixation to value-added chemicals, Nano Lett., 15 (2015) 3634-3639. 
[116] M. Wu, J. Zhang, C. Liu, Y. Gong, R. Wang, B. He, H. Wang, Rational design and fabrication of noble-metal-free $\mathrm{Ni}_{\mathrm{x}} \mathrm{P}$ cocatalyst embedded $3 \mathrm{D} \mathrm{N}-\mathrm{TiO}_{2} / \mathrm{g}-\mathrm{C}_{3} \mathrm{~N}_{4}$ heterojunctions with enhanced photocatalytic hydrogen evolution, ChemCatChem, 10 (2018) 3069-3077.

[117] L. Xiao, R. Lin, J. Wang, C. Cui, J. Wang, Z. Li, A novel hollow-hierarchical structured $\mathrm{Bi}_{2} \mathrm{WO}_{6}$ with enhanced photocatalytic activity for $\mathrm{CO}_{2}$ photoreduction, J. Colloid Interface Sci., 523 (2018) 151-158.

[118] N. Nie, F. He, L. Zhang, B. Cheng, Direct Z-scheme PDA-modified ZnO hierarchical microspheres with enhanced photocatalytic $\mathrm{CO}_{2}$ reduction performance, Appl. Surf. Sci., 457 (2018) 1096-1102.

[119] R.K. Chava, J.Y. Do, M. Kang, Hydrothermal growth of two dimensional hierarchical $\mathrm{MoS}_{2}$ nanospheres on one dimensional CdS nanorods for high performance and stable visible photocatalytic $\mathrm{H}_{2}$ evolution, Appl. Surf. Sci., 433 (2018) 240-248.

[120] A. Bafaqeer, M. Tahir, N.A.S. Amin, Well-designed $\mathrm{ZnV}_{2} \mathrm{O}_{6} / g-\mathrm{C}_{3} \mathrm{~N}_{4} 2 \mathrm{D} / 2 \mathrm{D}$ nanosheets heterojunction with faster charges separation via $\mathrm{pCN}$ as mediator towards enhanced photocatalytic reduction of $\mathrm{CO}_{2}$ to fuels, Appl. Catal. B: Environ., 242 (2019) 312-326.

[121] A. Meng, B. Zhu, B. Zhong, L. Zhang, B. Cheng, Direct Z-scheme $\mathrm{TiO}_{2} / \mathrm{CdS}$ hierarchical photocatalyst for enhanced photocatalytic $\mathrm{H}_{2}$-production activity, Appl. Surf. Sci., 422 (2017) 518-527.

[122] H. Jung, K.M. Cho, K.H. Kim, H.-W. Yoo, A. Al-Saggaf, I. Gereige, H.-T. Jung, Highly efficient and stable $\mathrm{CO}_{2}$ reduction photocatalyst with a hierarchical structure of mesoporous $\mathrm{TiO}_{2}$ on 3D fraphene with few-layered $\mathrm{MoS}_{2}$, ACS Sustain. Chem. Eng., 6 (2018) 5718-5724. [123] W. Dai, X. Hu, T. Wang, W. Xiong, X. Luo, J. Zou, Hierarchical $\mathrm{CeO}_{2} / \mathrm{Bi}_{2} \mathrm{MoO}_{6}$ heterostructured nanocomposites for photoreduction of $\mathrm{CO}_{2}$ into hydrocarbons under visible light irradiation, Appl. Surf. Sci., 434 (2018) 481-491.

[124] I. Hashemizadeh, V.B. Golovko, J. Choi, D.C.W. Tsang, A.C.K. Yip, Photocatalytic reduction of $\mathrm{CO}_{2}$ to hydrocarbons using bio-templated porous $\mathrm{TiO}_{2}$ architectures under $\mathrm{UV}$ and visible light, Chem. Eng. J., 347 (2018) 64-73.

[125] T. Noji, M. Kondo, T. Jin, T. Yazawa, H. Osuka, Y. Higuchi, M. Nango, S. Itoh, T. Dewa, Light-driven hydrogen production by hydrogenases and a Ru-complex inside a 
nanoporous glass plate under aerobic external conditions, J. Phys. Chem. Lett., 5 (2014) 24022407.

[126] T. Noji, T. Jin, M. Nango, N. Kamiya, Y. Amao, $\mathrm{CO}_{2}$ photoreduction by formate dehydrogenase and a Ru-complex in a nanoporous glass reactor, ACS Appl. Mater. Inter., 9 (2017) 3260-3265.

[127] N. Plumeré, O. Rüdiger, A.A. Oughli, R. Williams, J. Vivekananthan, S. Pöller, W. Schuhmann, W. Lubitz, A redox hydrogel protects hydrogenase from high-potential deactivation and oxygen damage, Nat. Chem., 6 (2014) 822.

[128] L. Chen, X. Tang, P. Xie, J. Xu, Z. Chen, Z. Cai, P. He, H. Zhou, D. Zhang, T. Fan, 3D printing of artificial leaf with tunable hierarchical porosity for $\mathrm{CO}_{2}$ photoreduction, Chem. Mater., 30 (2018) 799-806.

[129] A. Gebhardt, Understanding additive manufacturing : rapid prototyping, rapid tooling, rapid manufacturing, (2012).

[130] C. Barnatt, 3D Printing: Third Edition, CreateSpace Independent Publishing Platform, (2016).

[131] C. Zhao, C. Wang, R. Gorkin, S. Beirne, K. Shu, G.G. Wallace, Three dimensional (3D) printed electrodes for interdigitated supercapacitors, Electrochem. Commun., 41 (2014) 20-23. [132] A.K. Au, W. Huynh, L.F. Horowitz, A. Folch, 3D-printed microfluidics, Angew. Chem. Int. Ed., 55 (2016) 3862-3881.

[133] R. Bogue, 3D printing: an emerging technology for sensor fabrication, Sensor Rev., 36 (2016) 333-338.

[134] C.-Y. Lee, A.C. Taylor, S. Beirne, G.G. Wallace, 3D-printed conical arrays of $\mathrm{TiO}_{2}$ electrodes for enhanced photoelectrochemical water splitting, Adv. Energy Mater., 7 (2017) 1701060.

[135] A.A. Pawar, S. Halivni, N. Waiskopf, Y. Ben-Shahar, M. Soreni-Harari, S. Bergbreiter, U. Banin, S. Magdassi, Rapid three-dimensional printing in water using semiconductor-metal hybrid nanoparticles as photoinitiators, Nano Lett., 17 (2017) 4497-4501. 
[136] K.S. Novoselov, A.K. Geim, S.V. Morozov, D. Jiang, Y. Zhang, S.V. Dubonos, I.V. Grigorieva, A.A. Firsov, Electric field effect in atomically thin carbon films, science, 306 (2004) 666-669.

[137] J. Di, J. Xiong, H. Li, Z. Liu, Ultrathin 2D photocatalysts: electronic-structure tailoring, hybridization, and applications, Adv. Mater., 30 (2018) 1704548.

[138] Z. Chen, K. Mou, X. Wang, L. Liu, Nitrogen-doped graphene quantum dots enhance the activity of $\mathrm{Bi}_{2} \mathrm{O}_{3}$ nanosheets for electrochemical reduction of $\mathrm{CO}_{2}$ in a wide negative potential region, Angew. Chem. Int. Ed., 57 (2018) 12790-12794.

[139] J. Wu, X. Li, W. Shi, P. Ling, Y. Sun, X. Jiao, S. Gao, L. Liang, J. Xu, W. Yan, C. Wang, Y. Xie, Efficient visible-light-driven $\mathrm{CO}_{2}$ reduction mediated by defect-engineered $\mathrm{BiOBr}$ atomic layers, Angew. Chem. Int. Ed. Engl., 57 (2018) 8719-8723.

[140] M. Ou, W. Tu, S. Yin, W. Xing, S. Wu, H. Wang, S. Wan, Q. Zhong, R. Xu, Aminoassisted anchoring of $\mathrm{CsPbBr}_{3}$ perovskite quantum dots on porous $\mathrm{g}-\mathrm{C}_{3} \mathrm{~N}_{4}$ for enhanced photocatalytic $\mathrm{CO}_{2}$ reduction, Angew. Chem. Int. Ed., 57 (2018) 13570-13574.

[141] Y. Huang, D. Wu, S. Han, S. Li, L. Xiao, F. Zhang, X. Feng, Assembly of tin oxide/graphene nanosheets into 3D hierarchical frameworks for high-performance lithium storage, ChemSusChem, 6 (2013) 1510-1515.

[142] Y. Chao, J. Zheng, H. Zhang, Y. Ma, F. Li, Y. Tan, Z. Zhu, Constructing film photocatalyst with abundant interfaces between $\mathrm{CdS}$ and $\mathrm{Ni}_{3} \mathrm{~S}_{2}$ nanosheets for efficient photocatalytic hydrogen production, Energy Technol., 6 (2018) 2132-2138.

[143] W. Zhou, K. Zhou, D. Hou, X. Liu, G. Li, Y. Sang, H. Liu, L. Li, S. Chen, Threedimensional hierarchical frameworks based on $\operatorname{MoS}(2)$ nanosheets self-assembled on graphene oxide for efficient electrocatalytic hydrogen evolution, ACS Appl Mater Inter., 6 (2014) 2153421540.

[144] H. Tang, J. Luo, X.L. Tian, Y. Dong, J. Li, M. Liu, L. Liu, H. Song, S. Liao, Templatefree preparation of 3D porous Co-doped VN nanosheet-assembled microflowers with enhanced oxygen reduction activity, ACS Appl. Mater. Inter., 10 (2018) 11604-11612. 
[145] N. Zhang, S. Gan, T. Wu, W. Ma, D. Han, L. Niu, Growth control of $\mathrm{MoS}_{2}$ nanosheets on carbon cloth for maximum active edges exposed: An excellent hydrogen evolution 3D cathode, ACS Appl. Mater. Inter., 7 (2015) 12193-12202.

[146] T. Jia, X. Wang, F. Long, J. Li, Z. Kang, F. Fu, G. Sun, J. Chen, Facile synthesis, characterization, and visible-light photocatalytic activities of $3 \mathrm{D}$ hierarchical $\mathrm{Bi}_{2} \mathrm{~S}_{3}$ architectures assembled by nanoplatelets, Crystals, 6 (2016) 140.

[147] L.-P. Zhu, G.-H. Liao, N.-C. Bing, L.-L. Wang, Y. Yang, H.-Y. Xie, Self-assembled 3D $\mathrm{BiOCl}$ hierarchitectures: tunable synthesis and characterization, CrystEngComm, 12 (2010) 3791-3796.

[148] J. Tian, P. Hao, N. Wei, H. Cui, H. Liu, 3D $\mathrm{Bi}_{2} \mathrm{MoO}_{6}$ Nanosheet/TiO 2 Nanobelt heterostructure: enhanced photocatalytic activities and photoelectochemistry performance, ACS Catal., 5 (2015) 4530-4536.

[149] W. Wang, Z. Wang, J. Liu, Z. Zhang, L. Sun, Single-step one-pot synthesis of graphene foam/ $\mathrm{TiO}_{2}$ nanosheet hybrids for effective water treatment, Sci. Rep., 7 (2017) 43755.

[150] J. Hao, X. Wang, F. Liu, S. Han, J. Lian, Q. Jiang, Facile synthesis ZnS/ZnO/Ni(OH)2 composites grown on Ni foam: a bifunctional materials for photocatalysts and supercapacitors, Sci. Rep., 7 (2017) 3021.

[151] J. Hong, C. Chen, F.E. Bedoya, G.H. Kelsall, D. O'Hare, C. Petit, Carbon nitride nanosheet/metal-organic framework nanocomposites with synergistic photocatalytic activities, Catal. Sci. \& Technol., 6 (2016) 5042-5051.

[152] P. Zhang, C. Shao, M. Zhang, Z. Guo, J. Mu, Z. Zhang, X. Zhang, Y. Liu, Bi ${ }_{2} \mathrm{MoO}_{6}$ ultrathin nanosheets on $\mathrm{ZnTiO}_{3}$ nanofibers: a 3D open hierarchical heterostructures synergistic system with enhanced visible-light-driven photocatalytic activity, J. Hazard Mater., 217-218 (2012) 422-428. 